OPEN ACCESS

Edited by:

Oxana Bereshchenko,

University of Perugia, Italy

Reviewed by:

Alexandra K. Kiemer,

Saarland University, Germany

Francis Lin,

University of Manitoba, Canada

*Correspondence:

Claude Libert

Claude.Libert@IRC.VIB-UGent.be

Specialty section:

This article was submitted to Cytokines and Soluble Mediators in Immunity, a section of the journal

Frontiers in Immunology

Received: 22 March 2021 Accepted: 19 May 2021

Published: 04 June 2021

Citation:

Vanderhaeghen $T$, Beyaert $R$ and Libert $C$ (2021) Bidirectional

Crosstalk Between Hypoxia

Inducible Factors and Glucocorticoid

Signalling in Health and Disease.

Front. Immunol. 12:684085.

doi: 10.3389/fimmu.2021.684085

\section{Bidirectional Crosstalk Between Hypoxia Inducible Factors and Glucocorticoid Signalling in Health and Disease}

\author{
Tineke Vanderhaeghen ${ }^{1,2}$, Rudi Beyaert ${ }^{1,2}$ and Claude Libert ${ }^{1,2^{*}}$ \\ ${ }^{1}$ Centre for Inflammation Research, Flanders Institute for Biotechnology (VIB), Ghent, Belgium, ${ }^{2}$ Department of Biomedical \\ Molecular Biology, Ghent University, Ghent, Belgium
}

Glucocorticoid-induced (GC) and hypoxia-induced transcriptional responses play an important role in tissue homeostasis and in the regulation of cellular responses to stress and inflammation. Evidence exists that there is an important crosstalk between both GC and hypoxia effects. Hypoxia is a pathophysiological condition to which cells respond quickly in order to prevent metabolic shutdown and death. The hypoxia inducible factors (HIFs) are the master regulators of oxygen homeostasis and are responsible for the ability of cells to cope with low oxygen levels. Maladaptive responses of HIFs contribute to a variety of pathological conditions including acute mountain sickness (AMS), inflammation and neonatal hypoxia-induced brain injury. Synthetic GCs which are analogous to the naturally occurring steroid hormones (cortisol in humans, corticosterone in rodents), have been used for decades as anti-inflammatory drugs for treating pathological conditions which are linked to hypoxia (i.e. asthma, ischemic injury). In this review, we investigate the crosstalk between the glucocorticoid receptor (GR), and HIFs. We discuss possible mechanisms by which GR and HIF influence one another, in vitro and in vivo, and the therapeutic effects of GCs on HIF-mediated diseases.

Keywords: glucocorticoids, glucocorticoid receptor, HIF, hypoxia, inflammation

\section{GLUCOCORTICOIDS AND THE GLUCOCORTICOID RECEPTOR: A GENERAL INTRODUCTION}

Glucocorticoids (GCs; corticosterone in rodents, cortisol in humans) are important steroid hormones which play a role in several fundamental physiological processes such as lipolysis (1) and gluconeogenesis (2), inflammation (3), development (4) and reproduction (5), growth (6), mood and cognition $(7,8)$, and cardiovascular function (9). They are mainly synthesized in the cortex of the adrenal glands by enzymatic processing of cholesterol (10). Extra-adrenal GC production in the thymus, brain, vasculature, and epithelial barriers has also been observed, where GCs primarily regulate local immune responses (11). 


\section{The Biosynthesis of GCs, Their Regulation, and Biological Activity}

The adrenal GC production is regulated by the hypothalamicpituitary-adrenal (HPA) axis (Figure 1A). Under homeostatic, unstressed conditions, the adrenal glands release GCs into the bloodstream in a circadian and ultradian rhythm characterized by peak levels in the morning in humans and in the late afternoon/early night in nocturnal animals such as mice. Upon physiological (e.g. activated immune response) and emotional stress, the activity of the HPA axis is increased. Furthermore, the production of cytokines during inflammation also activates the HPA axis which forms an important regulatory process. GCs will limit the production of most cytokines to maintain homeostasis and guarantee the survival of the host to a life-threatening impact of excessive inflammation, which can be described as a tolerancelike mechanism (12).

When the HPA axis is stimulated, the hypothalamus secretes corticotropin-releasing hormone $(\mathrm{CRH})$ which subsequently induces the secretion of adrenocorticotropic hormone (ACTH) by the anterior pituitary in the bloodstream. ACTH will then bind to its receptor and stimulate the adrenal glands to synthesize and secrete GCs into circulation (13). Blood GC levels are regulated by a negative feedback loop, whereby the HPA axis is inhibited at different levels by GCs both in a genomic and nongenomic way (14). The total amount of GCs in circulation is controlled by the adrenal production, but extracellular binding proteins and intracellular enzymes regulate local GC activity. In plasma, $\sim 90 \%$ of circulating GCs are bound by corticosteroidbinding globulin $(\mathrm{CBG})$ and albumin, thereby leaving only a limited amount of circulating GCs in a free, biological active form (15). At sites of infection, proteases such as neutrophil elastases target CBG, causing the local release of bound GCs (16). Once the lipophilic GCs are released into the bloodstream, they diffuse through cell membranes to bind cytosolic glucocorticoid receptor (GR). This receptor is ubiquitously and constitutively expressed throughout the body, but exerts tissue-specific and cellular effects (17). The bioavailability of GCs in the cytoplasm is determined by the balance between active and inactive forms of GCs. Within cells, 11 $\beta$-hydroxysteroid dehydrogenase $(11 \beta$-HSD1/2) enzymes are responsible for the conversion of inactive cortisone/11-dehydrocortisone into active cortisol/ corticosterone, and vice versa (Figure 1B). Inflammatory cytokines are able to regulate the expression of $11 \beta$-HSD $1 / 2$ enzymes, thereby modulating GC activity locally (18).

\section{The GR Protein Structure}

The GR is a member of the nuclear receptor superfamily of transcription factors (TFs). It is a $97 \mathrm{kDa}$ protein encoded by the NR3C1/Nr3c1 gene (chromosome 5 in human, chromosome 18 in mouse). The GR protein contains an N-terminal domain (NTD), a DNA-binding domain (DBD), a hinge region, and a Cterminal ligand-binding domain (LBD) (19). In the NTD, the ligand independent activation function (AF1) is present which is responsible for the binding of co-factors, chromatin modulators, and the transcription machinery (20). The DBD contains two subdomains each containing a zinc finger important for specific GR DNA binding (proximal box) and GR dimerization (distal box) (21). The hinge region provides flexibility between the DBD
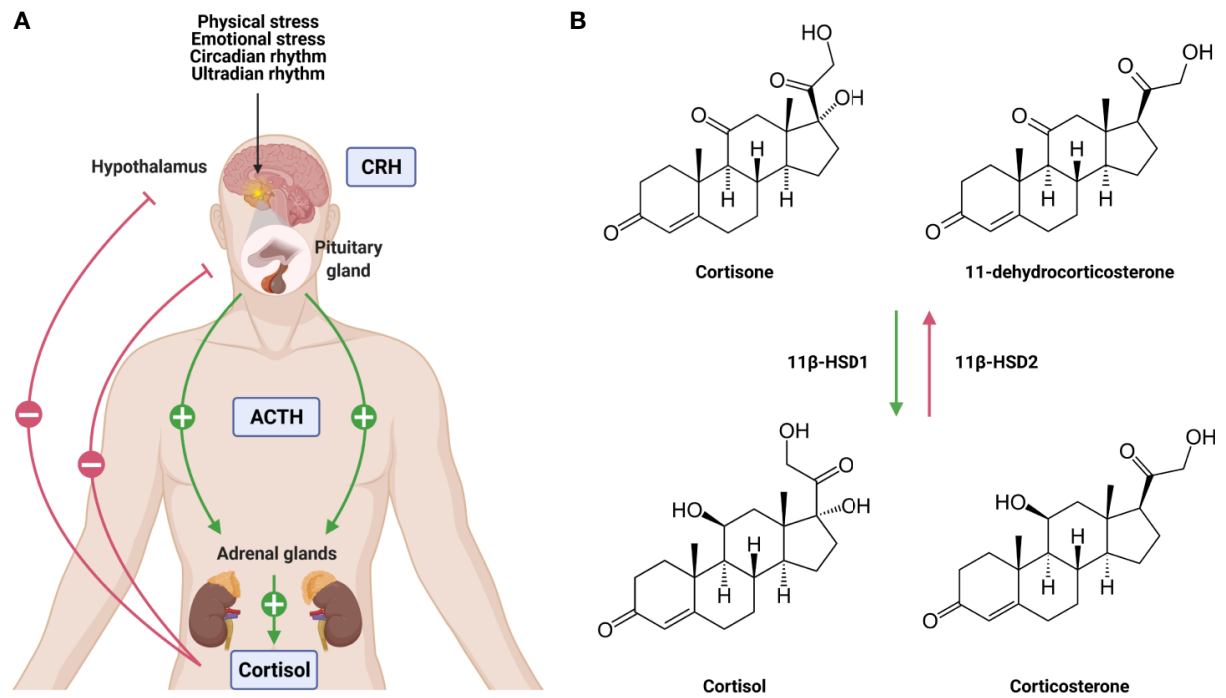

FIGURE 1 | The hypothalamic-pituitary-adrenal (HPA) axis (A) and the conversion of glucocorticoids (GCs) (B). (A) Under unstressed, homeostatic conditions GCs are released from the adrenal glands in the blood stream in a circadian and ultradian rhythm. Upon physiological and emotional stress, this release is increased. Stimulation of the HPA axis induces the secretion of corticotrophin releasing hormone $(\mathrm{CRH})$ by the hypothalamus which stimulates the release of adrenocorticotrophic hormone (ACTH) by the pituitary. This will lead to the production of GCs by the adrenal glands and the secretion into the blood stream. Blood GC levels regulate the hypothalamus and the pituitary via a negative feedback loop. (B) The lipophilic GCs diffuse freely through the plasma membrane. The bioavailability of the GCs is regulated by $11 \beta-H S D 1$ and $11 \beta-H S D 2$ which are responsible for the conversion of inactive cortisone/11-dehydrocortisone into active cortisol/corticosterone and vice versa. Figures created with Biorender. 
and the LBD and acts as a regulatory interface. The LBD contains a ligand binding pocket which is composed of $12 \alpha$-helices and $4 \beta$-sheets, and the ligand-dependent AF-2 domain. GR dimerization is also provided by a dimerization interphase in the LBD (22). Further, nuclear localization (NLS), nuclear export (NES), and nuclear retention (NRS) signals have been identified in the GR and are required for the subcellular traffic of GR (Figure 2A) (23).

\section{GR Signalling}

In the absence of bioactive ligand, the GR resides in the cytoplasm in a multiprotein chaperone complex. This chaperone complex is critical for the conformation of GR, in an ATP dependent manner, in which the ligand-binding cleft of GR is opened to allow GC binding with high affinity. Furthermore, the chaperone complex is important for nuclear translocation and activation of the GR. Upon ligand binding, the GR undergoes conformational changes leading to dissociation of the chaperone complex and translocation to the nucleus (24). Once in the nucleus, the GR transcriptionally activates or represses gene expression as a GR monomer or a GR dimer (or even a tetramer) usually via direct interaction with specific DNA sequences (25). In most tissues and in the presence of endogenous GCs during homeostasis, GR most frequently binds to DNA as a monomer and interacts with DNA via binding to GC response element (GRE) half-sites. When a binding site for another TF is in close proximity of the GRE halfsite, both elements are able to act as a composite site where the GR monomer and the other TF might interact in a positive or negative manner (26). Two GR monomers can also bind to DNA via interaction with inverted negative GREs and repress gene expression by recruitment of corepressors (27). When exogenous GCs like dexamethasone (DEX) and prednisolone are administered, the binding of the GR dimer to GREs is favoured at the cost of the GR monomer. Of course, GR homodimers are also formed under certain pathophysiological conditions, e.g. when GCs rise very high in the blood. Binding of GR homodimers induces transcriptional activation of genes, which indicates that the GR monomer is the most important for physiological functions whereas the GR dimer is crucial for the pharmacological and stress functions (28). GR can also interact with specific genome regions indirectly via tethering with other TFs such as nuclear factor $\kappa \mathrm{B}(\mathrm{NF}-\kappa \mathrm{B})$ and AP-1 (29). Additionally, GR is able to compete with other TFs for overlapping DNA binding sequences (30) of for the binding of co-factors $(31,32)$. Finally, GR can sequester other TFs to prevent them of binding to the DNA (Figure 2B) (33). Next to genomic effects, GR can also induce non-genomic effects which are not dependent on transcriptional activities or protein synthesis (34).

\section{THE PHYSIOLOGICAL REGULATION AND STRUCTURE OF HYPOXIA-INDUCIBLE FACTORS}

The discovery of how cells are able to sense and respond to low oxygen levels, known as hypoxia, has been rewarded in 2019 with the Nobel Prize in Physiology or Medicine, for Drs. Ratcliffe,
Kaelin and Semenza. The regulation of oxygen homeostasis and the access to an adequate oxygen supply is crucial for the survival of all aerobic organisms, including humans. During oxygen deprivation induced by low levels of haemoglobin or insufficient blood flow to specific organs, cells modulate their protein activity or change their transcriptional and post-transcriptional organisations (35). Cells will activate multiple genes involved in diverse biological processes such as cell survival and proliferation (36), glucose metabolism (37), and angiogenesis (38).

\section{Oxygen Sensing and the Importance of HIF Proteins}

The human body senses oxygen levels by different mechanisms. First, the carotid body located in the carotid artery senses oxygen and carbon dioxide levels in the blood. When the carotid body detects a decrease in blood oxygen levels, it transduces a signal to stimulate breathing, thereby increasing the acquisition of oxygen from the air (39). Second, an unexpected and novel role for the mouse olfactory system has been revealed as a peripheral oxygensensing system that enables mice to rapidly assess the oxygen level in the environment before the arterial blood becomes hypoxic (40). Also, oxygen-dependent enzymes such as 2-oxoglutaratedependent [2-OG, also known as $\alpha$-ketoglutarate $(\alpha-K G)$ ] oxygenases require oxygen for their activity. When oxygen levels decrease, their activity is inhibited. Prolyl hydroxylases (PHDs) are the best-characterized 2-OG-dependent oxygenases which negatively regulate hypoxia inducible factors (HIFs) (41), and thus operate as an "oxygen sensor" system. Additionally, mitochondria are also considered as a site of cellular oxygen sensing since they are responsible for the majority of oxygen consumption within cells. Oxygen is used at the terminal complex in the electron transport chain (ETC), where oxygen serves as the acceptor of protons, which have been stripped from metabolites in the ETC, forming $\mathrm{H}_{2} \mathrm{O}$. The production of mitochondrial reactive oxygen species (ROS) signals upon hypoxia was firstly demonstrated by Chandel et al. They have shown that HIF1 $\alpha$ is stabilized upon hypoxia by the generation of ROS by the mitochondrial ETC (42), and more specifically, the ROS generated by complex III (43). A possible explanation how mitochondrial ROS stabilize HIF proteins is by inhibiting PHDs and Factor inhibiting HIF1 (FIH). Hydroxylases can be modified post-translationally by redox signals. Since PHD2 is able to interact with other proteins (44), ROS signals can influence PHD2 activity by changing these protein-protein interactions. Another possibility is the oxidation of cysteine residues or attacking iron $\left(\mathrm{Fe}^{2+}\right)$ atoms $(45,46)$, which are important for PHD and FIH function, by ROS leading to the inactivation of these oxygen-dependent enzymes.

The master regulators involved in oxygen homeostasis and important for development, physiology, and disease are HIFs. They are members of the basic helix-loop-helix Per-Arnt-Sim (bHLH-PAS) transcription factor superfamily. HIFs are heterodimers containing an $\alpha$ - and $\beta$-subunit. Three $\alpha$ subunits are found in mammals, namely HIF $1 \alpha, \operatorname{HIF} 2 \alpha$, and $\mathrm{HIF} 3 \alpha$, which are oxygen-sensitive as they accumulate in hypoxia. The $\beta$-subunit, also known as the aryl hydrocarbon receptor nuclear translocator (ARNT), is constitutively expressed 


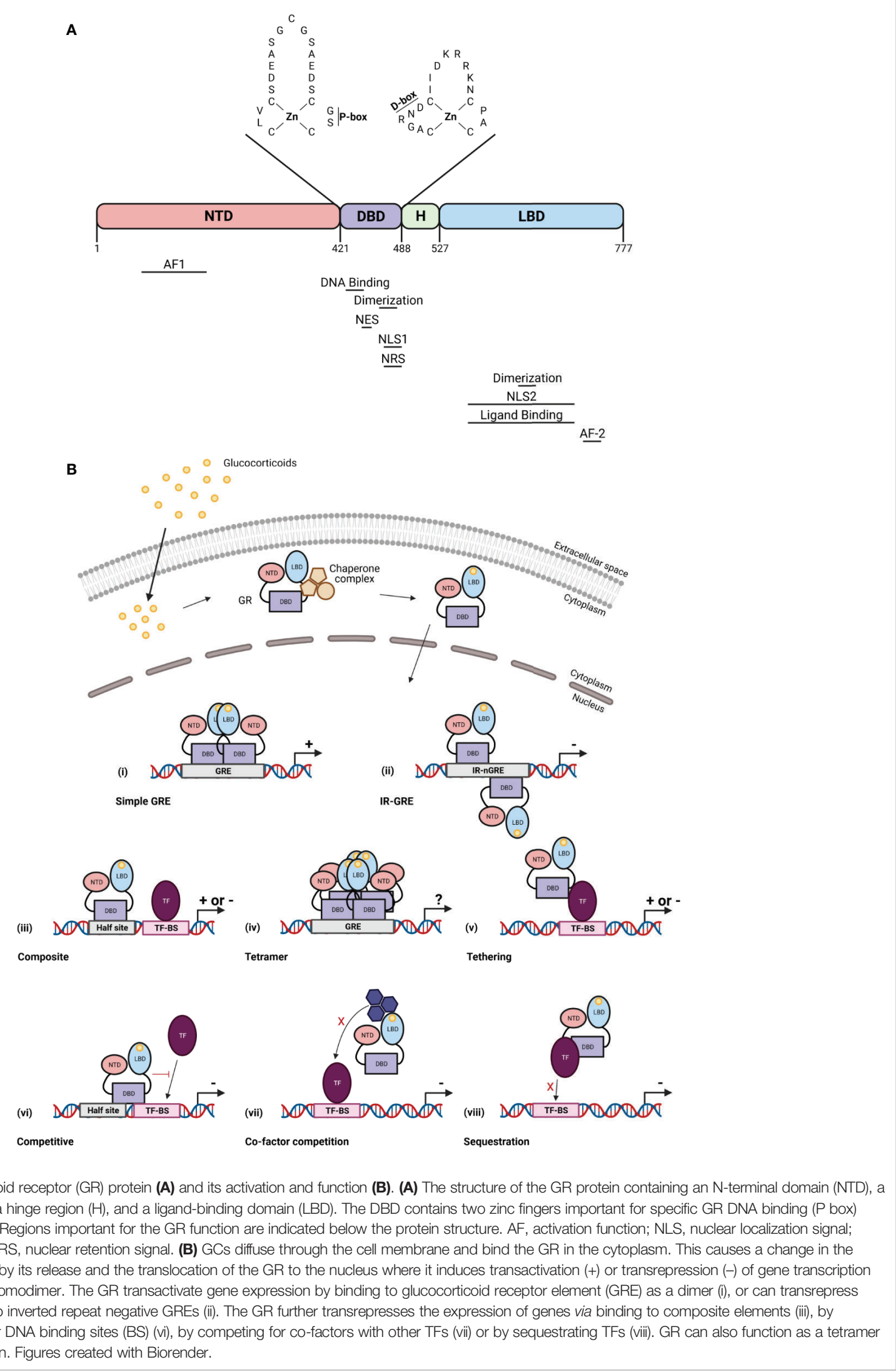


and not affected by hypoxia. HIF1 $\alpha$ and HIF1 $\beta$ contain an $\mathrm{N}-$ terminal bHLH and PAS domain, responsible for DNA binding and heterodimerization, respectively, and C-terminal transactivation domains (N-TAD and C-TAD). N-TAD is mandatory for target gene specificity and the stability, while CTAD interacts with co-activators e.g. p300 and CREB binding protein (CBP) required for full HIF activity and regulation of HIF target gene expression. The oxygen sensitivity of HIF $\alpha$ is conferred by an internal oxygen-dependent degradation domain (ODDD). Besides these domains, two nuclear localization signals
(N-NLS and C-NLS) are present, which direct the HIF protein to the nucleus. HIF $2 \alpha$ exhibits high structural similarity with HIF $1 \alpha$, but they differ in their transactivation domains leading to differences in target gene specificities. HIF $1 \alpha$ is ubiquitously expressed, while HIF $2 \alpha$ expression is more cell type specific like hepatocytes, adipocytes, endothelial cells, cardiomyocytes, interstitial cells, kidney glomeruli and neurons (47-52). HIF3 $\alpha$ is the dominant-negative regulator of the HIF pathway. Due to the absence of the ODDD, HIF1 $\beta$ is constitutively expressed in an oxygen-independent manner (Figure 3A).
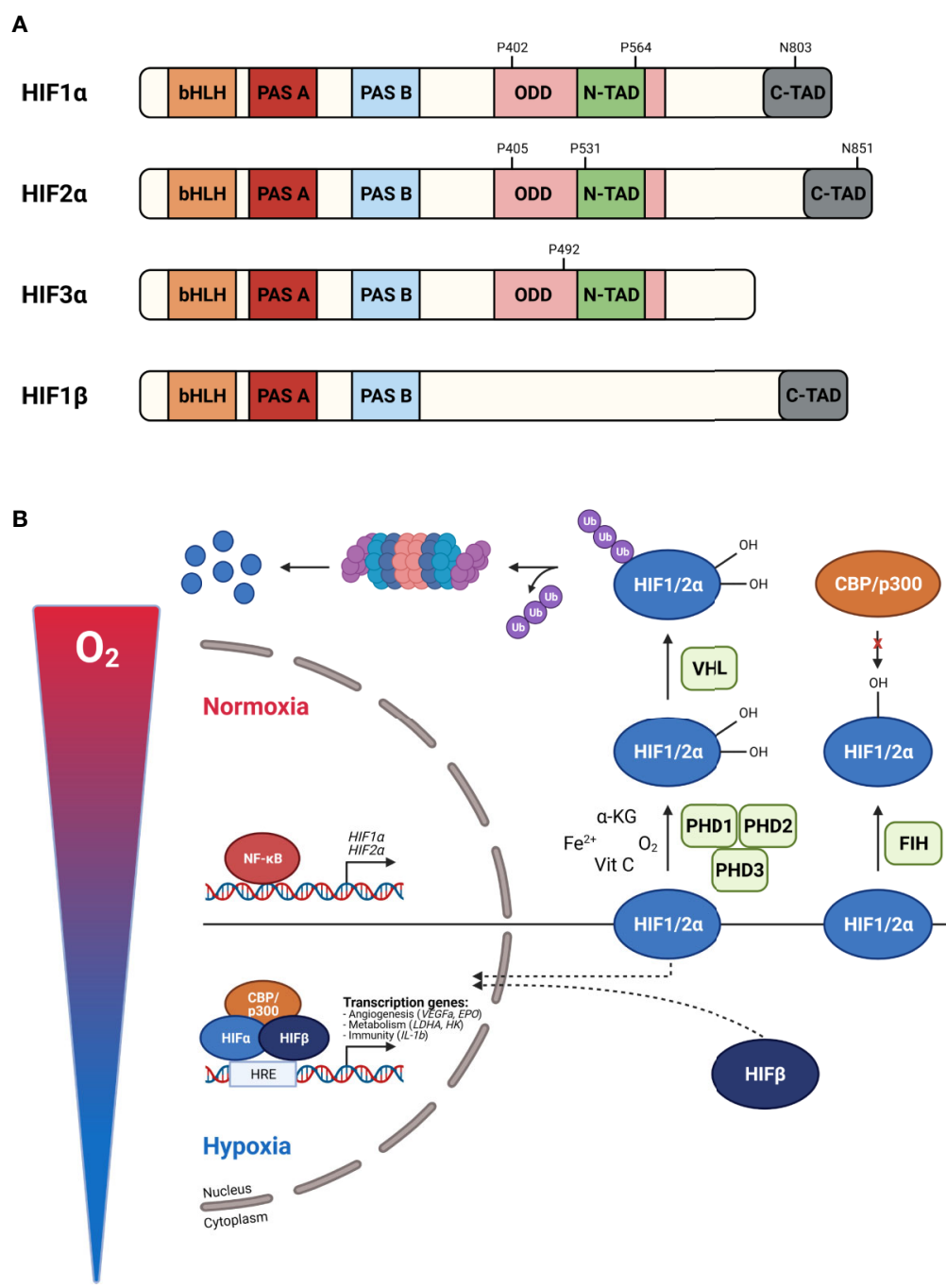

FIGURE 3 | Protein structure of hypoxia inducible factors (HIFs) (A) and their activity under normoxic and hypoxic conditions (B). (A) HIF proteins are basic helixloop-helix Per-Arnt-Sim (bHLH-PAS) transcription factors build up by an $\alpha$-subunit and $\beta$-subunit. HIF1 $\alpha$ consist of a bHLH and PAS domain, necessary for DNA binding and homodimerization, respectively. Further, an oxygen-dependent domain (ODDD) and two transactivation domains (N-TAD and C-TAD) are present. The stability and target gene specificity are determined by the N-TAD which overlaps with the ODDD. The C-TAD regulates the interaction with co-activators thereby activating gene transcription. HIF1 $\alpha$ and HIF2 $\alpha$ differ within their transactivation domain, while HIF3 $\alpha$ is known as the dominant-negative regulator. Due to the absence of the ODDD, HIF1 $\beta$ is constitutively expressed. (B) In normoxia, prolyl hydroxylases (PHDs) hydroxylate proline (P) residues in the ODDD leading to the binding of the von Hippel-Lindau protein ( $\mathrm{pVHL}$ ) followed by ubiquitination and degradation by the 26S proteasome. The factor inhibiting HIF1 (FIH) hydroxylates asparagine $(\mathrm{N})$ residues in the C-TAD, preventing the interaction of the C-TAD with co-activators thereby inhibiting gene transcription. When oxygen levels decrease, PHDs are inactivated, the HIF $\alpha$ subunits are stabilized, dimerize with $\mathrm{HIF} \beta$ and translocate to the nucleus. After CBP/p300 are recruited, gene transcription is induced by binding to hypoxia-responsive elements (HREs). Figures created with Biorender. 


\section{HIF Protein Regulation}

In physiological oxygen conditions, HIF $\alpha$ proteins are constantly produced and degraded by the $26 \mathrm{~S}$ proteasome. When oxygen is present, PHDs hydroxylate proline (Pro) residues present in the ODDD (Pro 402 and 564 for HIF1 $\alpha$, Pro 405 and 531 for HIF2 $\alpha$ ) inducing an ubiquitination reaction by the E3 ubiquitin ligase Von Hippel-Lindau protein (pVHL) followed by $26 \mathrm{~S}$ proteasome-mediated degradation. The activity of PHDs relies on the presence of oxygen, $\mathrm{Fe}^{2+}, \alpha-\mathrm{KG}$ and ascorbic acid (also known as vitamin $\mathrm{C}$ ). Each PHD has a different affinity for a certain HIF. HIF1 $\alpha$ is mainly regulated by PHD2, while PHD1 and PHD3 are the master regulators of HIF2 $\alpha$ (53-55). Mouse studies have reported that PHD2 deficiency causes defects in the developing heart and placenta leading to embryonic lethality between E12.5 and E14.5 (56, 57). Deletion of PHD1 and PHD3 is not lethal and only has tissue specific effects, because of their role in cellular metabolism in skeletal muscle and blood pressure in the central nervous system, respectively $(58,59)$. Hydroxylation of asparagine (Asn) residues in the C-TAD (Asn 803 for HIF1 $\alpha$ and Asn 851 for HIF2 $\alpha$ ) by FIH prevents the interaction of C-TAD with co-activators causing the inhibition of the transcriptional activity of HIF $\alpha$. Under hypoxic conditions, or in the absence of the cofactors $\mathrm{Fe}^{2+}, \alpha-$ KG or vitamins, PHDs are inactivated and HIF $\alpha$ hydroxylation is inhibited. The availability of HIF $\alpha$ can also be regulated at a transcriptional level via a crosstalk with other signalling pathways. For example, NF- $\kappa \mathrm{B}$ is able to bind the HIF $1 \alpha$ promotor and induces its transcription (60). Once the $\alpha$ subunits are stabilized, they dimerize with HIF1 $\beta$ and translocate to the nucleus. After co-factor recruitment, the heterodimeric complex binds to hypoxia responsive elements (HREs) containing the core sequence RCGTG (R: A/G) leading to the activation of target genes (Figure 3B).

\section{BIDIRECTIONAL CROSSTALK BETWEEN HIF AND GR}

\section{The Direct Effect of Hypoxia/HIF on GR Function and Vice Versa}

The presence of a crosstalk between hypoxia-dependent signalling pathways and GCs and their receptor have been described in several in vitro studies (Figure 4). Kodama et al. have been the first to provide evidence of an interaction between HIF and GR. They have identified that hypoxia-dependent gene expression and HRE activity in HeLa cells is enhanced by ligand-dependent activation of GR after DEX stimulation. Furthermore, they show that the LBD is essential for the induction of HRE-Luc activity in HeLa cells upon DEX stimulation, since the HRE-Luc activity is not altered when HeLa cells are transfected with a GR plasmid lacking the NTD or in the presence of the point mutation A458T causing impaired GR dimerization. Although they have no direct evidence of a clear protein-protein interaction between the GR LBD and HIF1, colocalization of GR and HIF1 in distinct compartments of the nucleus are shown (61). Subsequently, a functional role for hypoxia and HIF1 $\alpha$ in the regulation of GR mRNA and protein expression and the associated increased GC activity has been shown by Leonard et al. in human proximal tubular epithelial cells (HK-2 cells), indicating that there is an obvious crosstalk between HIF and GR. The upregulation of GR might occur through the binding of HIF1 $\alpha$ to one or more HRE sites in the NR3C1 promotor, thereby enhancing GR transcription (62). These results were confirmed in another study where GR expression is upregulated in mouse pituitary AtT-20 cells in hypoxic conditions by increased HIF $1 \alpha$ mRNA and protein expression levels (63).

In contrast to the previous studies, Wagner et al. demonstrate that the effect of hypoxia on human hepatoma HepG2 cells in combination with DEX stimulation leads to reduced HIF1 $\alpha$ DNA binding activity and HRE activity in a dose-dependent manner. Also, the expression of endogenous HIF1 $\alpha$ target genes is decreased. This indicates that DEX attenuates HIF1 $\alpha$ activity in a GR-dependent manner, since these effects are not present in a GR deficient human hepatoma Hep3B cell line and are restored upon transient expression of GR. They also report an unusual distribution of HIF1 $\alpha$ in the cytoplasm, which suggests a problem with nuclear translocation of HIF1 $\alpha$ (64).

\section{The Consequences of Hypoxia on the Anti-Inflammatory Actions of GCs}

Next to the direct effect of hypoxia/HIF on GR and vice versa, several in vitro studies describe the effect of hypoxia on the antiinflammatory actions of synthetic GCs. Hypoxia plays a key role in chronic lung diseases e.g. asthma and chronic obstructive pulmonary disease (COPD). The alveolar epithelial cells are directly exposed to changes in oxygen pressure in the arterial blood and to inhaled steroids (65). The exposure of A549 cells (immortalized human alveolar epithelial cells) to hypoxic conditions causes a downregulation of both GR mRNA and protein levels (66) and inhibits nuclear translocation of GR (67), which is in contrast with the results of Leonard et al. (62). This suggests that hypoxia has cell-type-specific effects on GR mRNA and protein levels (68). In the presence of normal oxygen levels, DEX inhibits the production of IL- 8 by A549 cells when stimulated with lipopolysaccharide (LPS). However, hypoxia significantly attenuates the DEX-mediated inhibition of IL-8 production in these cells (66). Charron et al. also demonstrate a reduced anti-inflammatory effect of DEX: stimulation of A549 cells with the pro-inflammatory cytokine IL-1 $\beta$ leads to increased CXCL8 production, which can be repressed by DEX, but in hypoxia the DEX response is less effective (Figure 4A). They show that this reduced DEX effect might be linked to the binding of HIF1 $\alpha$ to HREs present in the promotor of histone deacetylase 2 (HDAC2), which is normally recruited by an activated GR to repress NF- $\kappa \mathrm{B}$ mediated transcription in airway epithelial cells. However, binding of HIF1 $\alpha$ to the promotor leads to reduced HDAC2 transcription and less suppression of $\mathrm{NF}-\kappa \mathrm{B}$ mediated transcription of genes with known pro-inflammatory functions (69). 


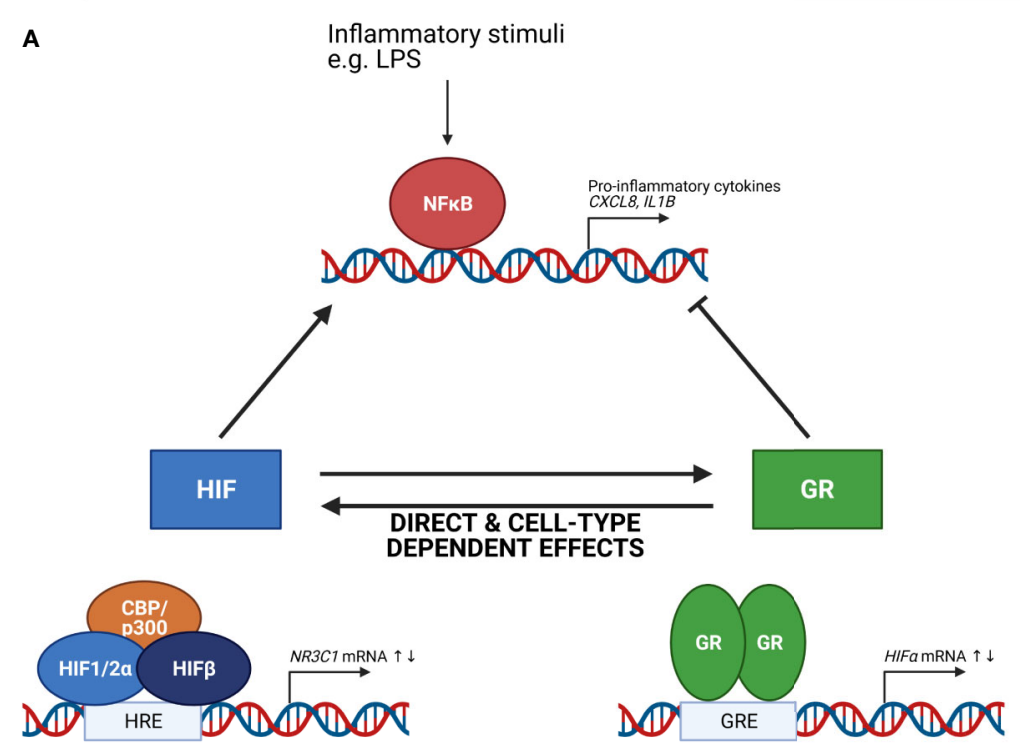

B

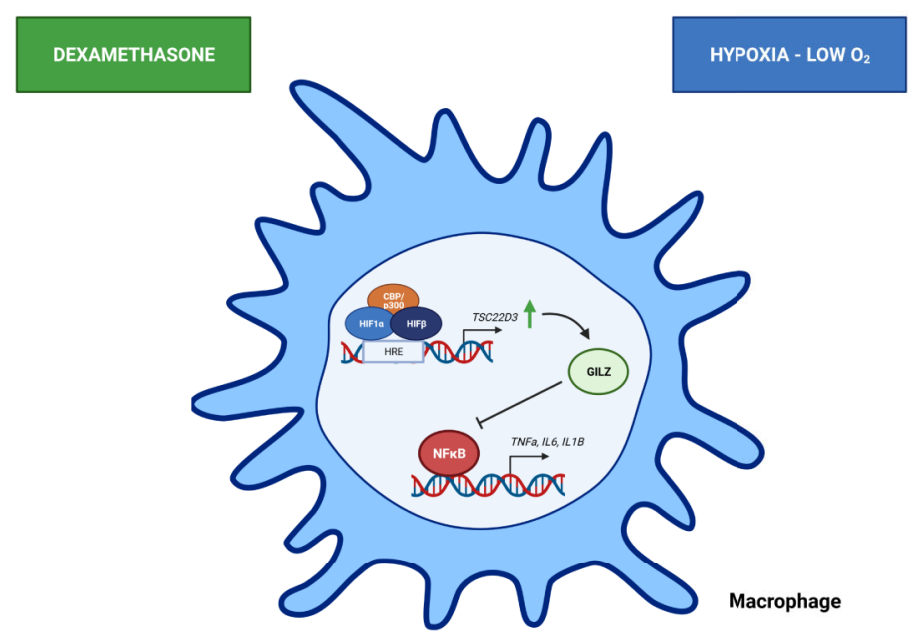

FIGURE 4 | The crosstalk between HIF and GR and its effect on NF-kB activity (A) and the effect of oxygen availability on immune cells (B). (A) Based on in vitro studies, HIF and GR have direct and cell-type dependent effects on each other, thereby increasing or repressing the transcription of HIF mRNA and N3RC1 mRNA genes. Inflammatory stimuli like lipopolysaccharide (LPS) induce NF-KB mediated transcription of genes encoding pro-inflammatory cytokines. HIF is known to stimulate this NF-KB mediated gene transcription, while GR will repress this. (B) Upon hypoxic conditions, the expression of GC-induced leucine zipper (GILZ) encoded by the TSC22D3 gene is upregulated, thereby inhibiting the expression of pro-inflammatory cytokines mediated by NF-kB. When macrophages are pretreated with dexamethasone, a synthetic GC, the effects are amplified. Figures created with Biorender.

\section{Immune Cells and the Role of Oxygen Availability}

Oxygen availability is also important for the functional behaviour of immune cells. Hypoxia is able to activate monocytes, macrophages and dendritic cells by altering their gene expression and cytokine secretion (70-73). GC-induced leucine zipper (GILZ) is encoded by the TSC22D3 gene, which is known as a DEX-inducible gene and is highly expressed in cells of the immune system (74). GILZ is able to inhibit the activation of macrophages and the production of proinflammatory cytokines and inflammatory mediators upon exposure to LPS (75). The exposure of macrophages to hypoxic conditions significantly upregulates GILZ mRNA expression, thereby inhibiting the production and secretion of proinflammatory cytokines IL-1 $\beta$ and IL-6. When pre-treated with DEX these effects are amplified. These results indicate that GILZ prevents the overactivation of immune cells and overproduction of 
pro-inflammatory cytokines in hypoxic microenvironments and might be involved in systemic adaptation to hypoxia (Figure 4B) (76). In A549 cells, hypoxia induces the expression COX-2 via NF$\kappa \mathrm{B}$, which is suppressed by DEX. The inhibitory effects of DEX on hypoxia-induced COX-2 is mediated by GILZ via a physical interaction between GILZ and HIF1 $\alpha$ (77).

Macrophages are known to be key players in inflammatory diseases. Next to their protective immunological function, they also induce the production of pro-angiogenic cytokines and growth factors such as vascular endothelial growth factor (VEGF-A) and basic fibroblast growth factor (FGF-2) thereby promoting angiogenesis (78). Upon hypoxia, the polarization of macrophages is promoted towards the activated, anti-inflammatory M2 phenotype, and not to the pro-inflammatory M1 phenotype. This causes an increased the expression of VEGF and decreased the release of pro-inflammatory cytokines, thereby regulating macrophage functions including tumour promotion in cancer (79). It is known that GCs are angiostatic and are used to tread angiogenesis-related diseases such as solid tumours. They regulate angiogenesis via the suppression of proliferation, migration and sprouting in endothelial cells and by reducing the expression or secretion of cytokines and proteins involved in angiogenesis (80). Since both hypoxia and GCs are involved in angiogenesis and influence the macrophage function e.g. by inducing GILZ expression, it is possible that the hypoxic tumour environment in combination with GC treatment also causes the upregulation of GILZ expression and thereby preventing overactivation of immune cells. However, further investigation is necessary to elucidate the connection between hypoxia, GCs and GILZ expression and macrophage polarization. Must be added at the end of this paragraph: An overview of the most essential key studies concerning the bidirectional crosstalk between GCs and HIF can be found in Table 1 .

\section{The In Vivo Crosstalk Between HIF and GR and Its Role in Inflammation}

From these in vitro studies, a dynamic interaction between oxygen concentration and GR function mediated through HIF1 $\alpha$ has become clear (Figure 4A). Also in vivo studies using zebrafish have identified new activators of the HIF signalling pathway in the liver e.g. betamethasone (BME) and DEX, synthetic GR agonists. These GCs activate HRE reporters in a GR dependent manner (81), although via a nontranscriptional route since these HIF transcriptional responses were still present when the GR DBD harbours a point mutation (R443C; R484C in mouse and R477C in human), a missense mutation in the DBD thereby largely eliminating the transcriptional activity of GR (96). They suggest a mechanism by which GCs stabilize HIF proteins via the degradation of pVHL (81). Upregulation of the HIF signalling in $v \mathrm{hl} \mathrm{l}^{-1-}$ zebrafish represses the GR activity and dampens its responsiveness to BME. Also endogenous cortisol levels were reduced, most likely due to HIF-mediated downregulation of POMC activity. The inhibition of the HIF pathway leads to a significant increase in both GR activity and cortisol levels (97). These results are confirmed by Marchi et al. They have also demonstrated the repression of GR activity and its reduced responsiveness to exogenous GCs when HIF protein levels are upregulated in $v h l^{--}$zebrafish. Furthermore, cortisol levels were also reduced suggesting that HIF signalling can act both at the level of the hypothalamus by inhibiting Pomc expression and intracellularly by blocking the transcriptional activity of GR itself (82). A recent

TABLE 1 | Overview of key studies concerning the bidirectional crosstalk between GC signalling and HIF mediated pathways.

\begin{tabular}{|c|c|c|c|}
\hline & Purpose & Results & References \\
\hline \multirow[t]{5}{*}{ In vitro } & $\begin{array}{l}\text { DEX effect on HeLa cells under } \\
\text { hypoxic conditions }\end{array}$ & $\begin{array}{l}\text { Induction of hypoxia-dependent gene expression } \\
\text { Increased HRE-luciferase activity } \\
\text { The LBD of GR is necessary for HRE-luciferase activity }\end{array}$ & (61) \\
\hline & $\begin{array}{l}\text { Exposure of HK-2 cells or AtT-20 } \\
\text { cells to hypoxia }\end{array}$ & $\begin{array}{l}\text { Upregulation of GR mRNA and protein levels due to binding of HIF1 } \alpha \text { to HREs present in the NR3C1 } \\
\text { promotor }\end{array}$ & $(62,63)$ \\
\hline & $\begin{array}{l}\text { The effect of GCs on HIF1 } \alpha \text { function } \\
\text { (HepG2 cells) }\end{array}$ & $\begin{array}{l}\text { Attenuation of HIF1 } \alpha \text { activity upon hypoxia and DEX stimulation as a results of reduced DNA binding } \\
\text { and HRE activity associated with problems with HIF1 } \alpha \text { nuclear translocation }\end{array}$ & (64) \\
\hline & $\begin{array}{l}\text { Characterization of the hypoxic effect } \\
\text { on GR levels and its anti- } \\
\text { inflammatory actions in A549 cells }\end{array}$ & $\begin{array}{l}\text { Hypoxia causes a time-dependent downregulation of GR mRNA and protein levels and inhibits GR } \\
\text { nuclear translocation } \\
\text { The anti-inflammatory effect of DEX is attenuated when A549 cells are exposed to hypoxia and } \\
\text { stimulated with LPS or IL-1 } \beta\end{array}$ & $(66,67,69)$ \\
\hline & $\begin{array}{l}\text { Effect of chemical hypoxia }\left(\mathrm{CoCl}_{2}\right) \\
\text { and/or DEX on RAW264.7 cells }\end{array}$ & $\begin{array}{l}\text { GILZ is upregulated by hypoxia and is further increased upon DEX stimulation to prevent overactivation } \\
\text { of immune cells (macrophages) and overproduction of pro-inflammatory cytokines (inhibition of IL-1 } \beta \\
\text { and IL-6 production) }\end{array}$ & (76) \\
\hline In vivo & $\begin{array}{l}\text { How is hypoxia affecting the } \\
\text { endogenous GC pathway and vice } \\
\text { versa in zebrafish larvae? }\end{array}$ & $\begin{array}{l}\text { GCs stabilize HIF via pVHL degradation } \\
\text { HIF represses GR activity and the GR response to exogenous GCs (e.g. BME) in } v h^{\digamma^{--}} \text {zebrafish larvae } \\
\text { Cortisol levels are reduced by HIF due to repression of POMC expression and intracellular blocking the } \\
\text { transcriptional activity of GR }\end{array}$ & $(81,82)$ \\
\hline $\begin{array}{l}\text { GCs in } \\
\text { AMS }\end{array}$ & $\begin{array}{l}\text { Prophylactic effect of GCs when } \\
\text { ascending to high altitude }\end{array}$ & $\begin{array}{l}\text { Administration of GCs (DEX and prednisolone) prior to ascending to high altitude reduces the } \\
\text { symptoms of AMS (suppresses inflammatory pathways, reduces vascular permeability and } \\
\text { vasoconstriction, improves arterial oxygenation and induces a better antioxidant-oxidant balance) }\end{array}$ & (83-88) \\
\hline $\begin{array}{l}\text { Perinatal } \\
\text { hypoxia } \\
\text { and GCs }\end{array}$ & $\begin{array}{l}\text { Effect of GCs during perinatal } \\
\text { hypoxia }\end{array}$ & $\begin{array}{l}\text { Neonatal hypoxia leads to the activation of the HPA axis in the neonates and causes higher GC levels } \\
\text { GCs can have neuroprotective effects on neonatal HI-induced brain damage } \\
\text { Ideal timing, dose and duration of GCs is necessary to prevent neurotoxic effects }\end{array}$ & $\begin{array}{l}(89,90) \\
(91-93) \\
(94,95)\end{array}$ \\
\hline
\end{tabular}


study by Watts et al. propose HIF1 $\alpha$ as a vital regulator of steroidogenesis by controlling the expression of enzymes involved in steroid production (98).

In the presence of inflammation, an important role for the GR-HIF1 $\alpha$ signalling pathway has been implicated by Lu et al. (99). Immune mediated hepatic injury (IMH) caused by LPS leads to a decrease in GR protein levels in myeloid derived suppressor cells (MDSCs), which are known to be negative regulators of the immune response (100). However, when these MDSCs are treated with DEX, GR expression is restored followed by an ameliorated mortality and reduced inflammatory insults in IMH. This implies that the GR signalling pathway in MDSCs is a potential therapeutic target in treating innate immune cell-mediated hepatic injury. They also elucidate the suppression of HIF1 $\alpha$ and HIF $1 \alpha$ mediated glycolysis in MDSCs thereby promoting the immune suppressive activity in MDSCs (99). Pulmonary arterial hypertension (PAH) is a progressive and life-threatening disease with poor prognosis characterized by pulmonary vasoconstriction and increased pulmonary vascular resistance leading to right ventricular failure, fluid overload and eventually death (101). The infiltration of inflammatory cells e.g. T cells, B cells, macrophages and dendritic cells is typically present in the pulmonary vascular lesions of $\mathrm{PAH}$ patients (102). A critical role for serum GC regulated kinase 1 (SGK1 ) in the pro-inflammatory response in hypoxia-induced $\mathrm{PAH}$ is demonstrated. In the absence of SGK-1, the hypoxia-induced PAH development and pulmonary arterial remodelling is ameliorated, and the production of pro-inflammatory cytokines such as TNF $\alpha$ and IL-6 are inhibited. This suggest that SGK-1 plays a critical role in $\mathrm{PAH}$ development and might be a potential therapeutic target (103).

Based on these in vitro and in vivo studies, a bidirectional crosstalk between GR and HIF is present. However, more studies using animal models will be necessary to elucidate this interaction in more detail and how important this crosstalk is in inflammatory disease models. Further understanding of the GR-HIF crosstalk might lead to the development of alternative therapeutic strategies.

\section{IMPACT OF GCs ON ACUTE MOUNTAIN SICKNESS AND THE IMPORTANCE OF NF-KB}

Hypoxia and inflammation are unequivocally linked (104). Just as hypoxia causes inflammation by stimulating NF- $\mathrm{KB}$ gene transcription and the production of pro-inflammatory cytokines, inflamed tissue can also become hypoxic (105). The increased demand for oxygen and decreased oxygen supply are the main reasons why tissue becomes hypoxic during inflammation. The metabolic activity following an immunogenic insult is enlarged in the inflamed tissue and requires an increased synthesis of inflammatory cytokines and enzymes leading to a higher oxygen demand (106). Additionally, the influx of immune cells at the site of inflammation leads to more oxygen consumption and cellular hypoxia (105). Another cause of hypoxia during inflammation is disrupted oxygen delivery due to vascular dysfunction (107). Therefore, both an increased oxygen consumption and decreased oxygen delivery finally lead to tissue hypoxia during inflammation.

\section{The Prophylactic Effect of Synthetic GCs When Ascending to High Altitude}

Millions of people live permanently at high altitude. The inhabitants living at the highest altitude are found in $\mathrm{La}$ Rinconada in the Southern of Peru, where the altitude is $5100 \mathrm{~m}$ and only 7000 people live there. However Cerro de Pasco in Peru with an altitude of $4300 \mathrm{~m}$ has up to 75000 inhabitants and more than 1 million people reside at El Alto in Bolivia (altitude $4100 \mathrm{~m}$ ) (Figure 5) (108). In the recent years, the interest in carrying out activities at high altitudes has increased. People travel to regions of high altitudes (i.e. higher than $2500 \mathrm{~m}$ ) for work, permanent residence, sports and tourism. However, when ascending to high altitude, people are exposed to hypobaric hypoxia. Dependent on the length and time spent at high altitude, this can result in the development of high altitude illnesses encompassing pulmonary and cerebral syndromes which occur in non-acclimatized individuals shortly after rapid ascent $(109,110)$. Acute mountain sickness (AMS) is the most common syndrome and is characterized by headache and can also be accompanied by nausea, loss of appetite, disturbed sleep, fatigue and dizziness within $12 \mathrm{~h}$ after ascent. A grading system that is used for the diagnosis of AMS is the Lake Louis self-assessment questionnaire (LLS) (111-113). AMS is a phenomenon of systemic hypoxia, vascular leakage and increased levels of circulating pro-inflammatory cytokines which can lead to the development of high altitude pulmonary edema (HAPE) or high altitude cerebral edema (HACE) and are a potentially fatal consequence $(109,114)$.

Several clinical trials to prevent AMS have been performed in which acetazolamide and synthetic GCs such as DEX, budesonide and prednisolone were used. Acetazolamide has been the first drug used in a prophylactic manner, however symptoms were only partly controlled and the drug caused some undesirable side effects (83). Prophylactic treatment with GCs is able to reduce the symptoms of AMS when administered prior to ascending to high altitude (83-88). Both DEX and prednisolone are able to suppress inflammatory pathways (115), reduce vascular permeability and vasoconstriction (116), improve arterial oxygenation (88) and induce a more favourable antioxidant-oxidant balance (117). Budesonide, in contrast to DEX and prednisolone, is not recommended for the prevention of AMS, although it is able to reduce the heart rate and increases the oxygen saturation $(118,119)$. Next to synthetic GCs, clinical trials using non-steroidal anti-inflammatory drugs (NSAIDs) e.g. ibuprofen against AMS suggest that NSAIDs might be a safe and effective alternative medicine in the prevention of AMS (120). Further, large randomized controlled clinical trials are necessary to look in more detail to the prophylactic effect of budesonide in AMS. The fact that GCs prevent AMS may suggest that AMS is in fact nothing else than a hypoxia-induced general inflammatory response. Also, more clinical trials comparing the benefits of NSAIDs to synthetic GCs in the prevention of AMS are recommended. 


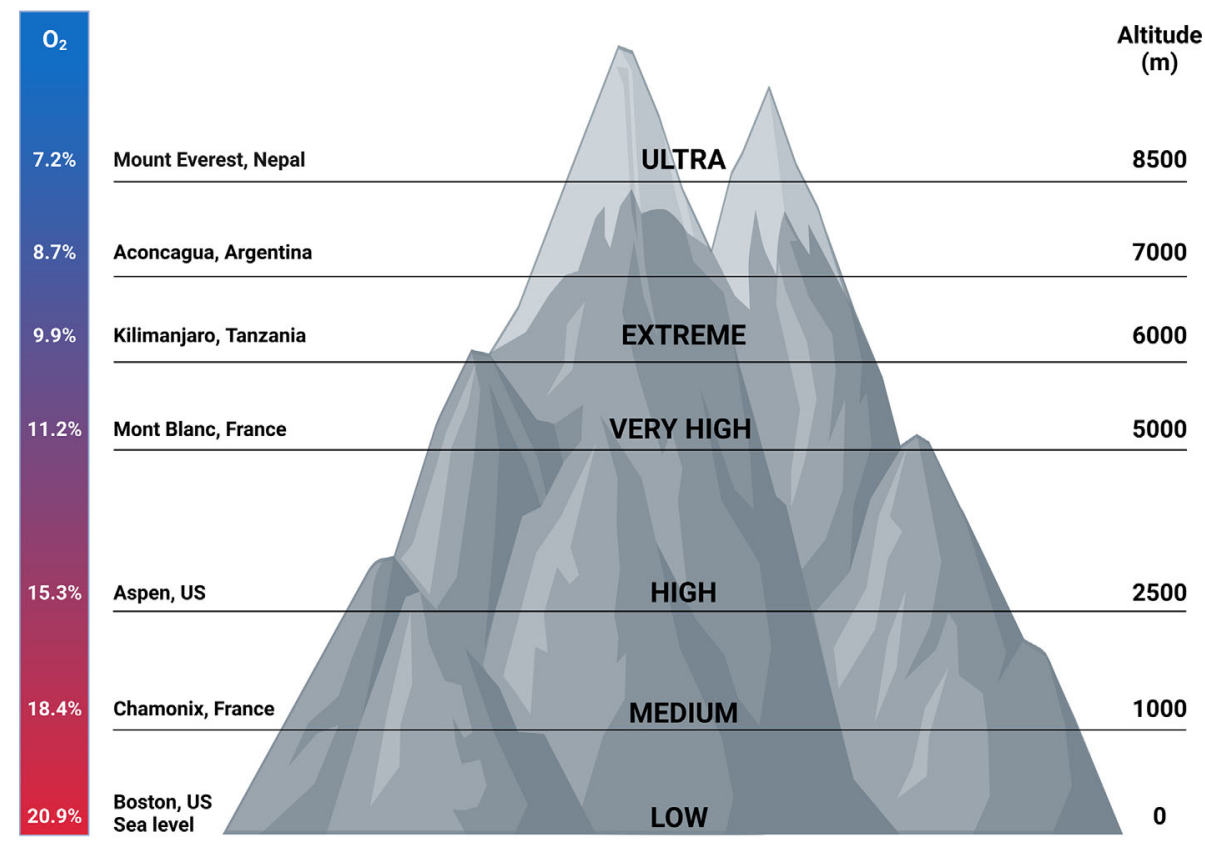

FIGURE 5 | Correlation between altitude and oxygen concentrations. Millions of people live permanently at high altitude. Also travelling to regions of high altitudes has gained interest throughout the years. In this figure, oxygen concentrations correlated with certain altitudes are depicted. In addition, the grade of hypoxia present at certain places worldwide are shown. Figures created with Biorender.

\section{How Does Hypoxia Cause Generalized Inflammation? \\ Physical Interaction Between NF-KB and HIF Proteins}

When humans ascent to high altitude and are exposed to hypoxic conditions, hypoxia itself is able to promote several TFs such as NF- $\kappa \mathrm{B}$ thereby stimulating the production of pro-inflammatory cytokines like TNF $\alpha$ and IL-6 (121). NF- $\mathrm{KB}$ is a family of TFs composed of RelA (p65), RelB, c-Rel, NF-kB1 (p50/p105) and NF- $\mathrm{\kappa B} 2$ (p52/p100). Different stimuli are able to activate these different subunits e.g. bacterial LPS, viral pathogens, cytokines and growth factors. NF- $\mathrm{KB}$ activation requires the degradation of the inhibitory proteins such as IKBs. Once they are

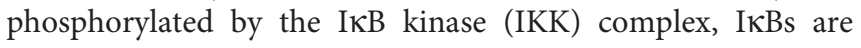
degraded by the proteasome and the NF- $\mathrm{KB}$ subunits can translocate to the nucleus to activate their target genes. One of these target genes is the HIF $\alpha$ subunit, thereby increasing its transcription (122). Several studies have reported the physical interaction between HIF and NF- $\kappa$ B. Hypoxia itself is also able to stimulate the activation of NF- $\mathrm{kB}$. In the presence of hypoxia, PHD1 activity is inhibited thereby decreasing PHD-dependent hydroxylation of IKK $\beta$, since IKK $\beta$ contains a conserved motif for PHD hydroxylation. This results in the phosphorylation of IKK $\beta$ and liberation of NF-KB from the cytoplasm (123). It is shown that HIF1 $\alpha$ binds to RelA in EGF-induced cells (124). Also a novel and specific interaction between NF- $\mathrm{KB}$ essential modulator IKK $\gamma$ (NEMO) and HIF2 $\alpha$ has been reported by Bracken et al. This interaction enhances the transcriptional activity of HIF $2 \alpha$ in normoxia in which NEMO promotes $\mathrm{CBP} / \mathrm{p} 300$ recruitment to HIF2 $\alpha$ (125). HIF $1 \beta$ is also able to interact physically with NF- $\kappa B$. Namely, in CD30 stimulated cells, HIF1 $\beta$ interacts with RelB and p52 subunits thereby promoting NF- $\kappa B$ mediated transcription (126). Next to hypoxia, HIF is also induced by growth factors such as insulinlike growth factor 1 and platelet-derived growth factor, cytokines like TNF $\alpha$ and IL-1, and ROS, all of which are activators of NF$\kappa B$ (Figure 6). This learns us that NF- $\kappa B$ functions as a direct modulator of HIF expression by regulating basal, TNF $\alpha$ and hypoxia-induced HIF expression (127-129). More elaborate studies will be necessary to determine whether the physical interaction between HIF and NF- $\mathrm{KB}$ is dependent on DNAbinding or is the result of protein-protein interactions. This is important, as more precise intervention strategies, involving GR or not, can then be developed.

\section{Systemic Inflammation in Response to High Altitude}

It has been shown that HIF $1 \alpha$ also plays an important role in promoting the expression of NF- $\mathrm{\kappa B}$ regulated inflammatory cytokines in macrophages after LPS (130). In humans ascending to high altitude, Hartmann et al. have reported elevated levels of the pro-inflammatory cytokine IL-6, the inflammatory marker IL-1 receptor antagonist (IL-1 ra) and Creactive protein (CRP) in the blood compared to normal levels. This demonstrates the presence of moderate systemic inflammation in response to high altitude (131). Also other studies have shown that exposure to hypoxia of rodents and 


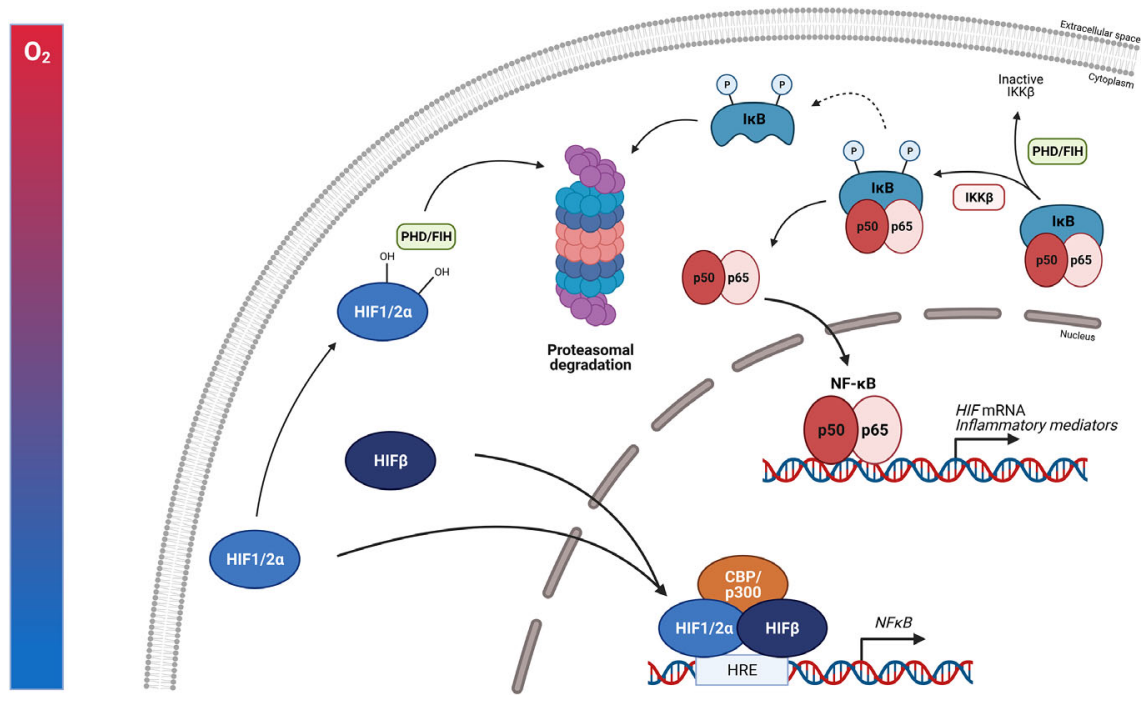

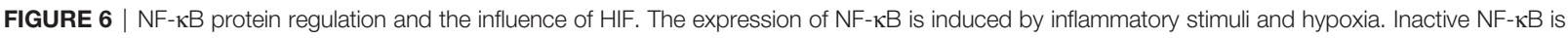
composed of a p50 and p65 subunit. The activation of this complex requires the degradation of inhibitory protein IкB. The phosphorylation of IкB by the $\beta$ subunit of the $I_{\kappa B}$ complex $(\mathrm{IKK} \beta)$ leads to the degradation of $I_{\kappa B}$ by the $26 S$ proteasome. Once degraded, the NF- $\mathrm{BB}$ heterodimer can translocate to the nucleus where it can activate the transcription of inflammatory genes as well as HIF. PHDs and FIH can regulate the activation of NF- $\kappa B$ by controlling the IKK $\beta$ activity. Upon hypoxia, HIF heterodimers can translocate to the nucleus, bind to HREs and induce the transcription of numerous genes including NF- $\kappa \mathrm{B}$. Figures created with Biorender.

humans causes increased vascular leakage and oxidative stress with elevated NF- $\mathrm{KB}$ expression in the lungs followed by significantly higher levels of pro-inflammatory cytokines IL-1, IL-6 and TNF $\alpha$ (132-134). Circulating chemokines known to recruit and activate leukocytes during inflammation such as macrophage inflammatory protein $1 \alpha(\mathrm{MIP}-1 \alpha)$ and monocyte chemoattractant protein 1 (MCP-1) are also significantly upregulated in HAPE susceptible individuals (fast ascending mountaineers with previous episodes of HAPE) which is suggestive for chronic inflammation (135). DEX is able to block the production of MCP-1 generated by hypoxic alveolar macrophages to increase capillary permeability $(136,137)$. It also blocks the formation of migration inhibitory factor (MIF) (138). The high recurrence rate of HAPE susceptibility might point towards a genetic predisposition linked with PAH. For example, a missense mutation in the JAK2 gene represents a good candidate gene for $\mathrm{PAH}$ and the possible development of HAPE upon ascending to high altitude. Also variants in the CYP1B1 and HRG gene have been identified in HAPE susceptible mountaineers (139). Therefore, the identification of more candidate gene polymorphisms in the pathogenesis of HAPE in combination with its prevention and treatment will be of great importance in the better understanding of the disease and formulating new strategies to deal with it.

A recent prospective observational trial has shown that several pro-inflammatory cytokines and chemoattractant proteins are increased after $24 \mathrm{~h}$ when non-acclimatized humans ascend to high altitude and can be associated with an increased LLS and the clinical symptoms for AMS. In blood samples of these individuals, levels of IL-1 $\beta, \mathrm{MCP}-1$ and its target protein VEGFA are increased at high altitude (140). When AMS further develops into HACE, both in humans and rats the highaltitude hypoxia causes an increase in circulating TNF $\alpha$, IL- $1 \beta$ and IL-6 cytokines. Also the stress hormone CRH is significantly increased. In rats, this has been associated with the upregulation of pro-inflammatory cytokines which can be blocked with a $\mathrm{CRH}$ receptor type 1 (CRHR1) antagonist. Based on these findings, one could suggest that the hypoxia-activated $\mathrm{CRH}$ and its CRHR1 signalling might be important for the induction AMS and its pro-inflammatory response (141).

In general, ascending to high altitude of non-acclimatized humans causes the development of AMS, which can further develop into HAPE or HACE. This is clearly associated with the induction of a pro-inflammatory response, most likely linked with a higher NF- $\kappa \mathrm{B}$ activity and perhaps the involvement of $\mathrm{CRH}$ and the CRHR1 signalling. Small scale clinical trials suggest a prophylactic effect of acetazolamide and GCs such as DEX and prednisolone against AMS probably by reducing NF- $\kappa \mathrm{B}$ activity and the production of pro-inflammatory cytokines (Figure 7). It would be of great interest to conduct large scale clinical trials with healthy individuals ascending to high altitude which could provide new insights into the body's reaction to hypoxia. The exploration of possible mechanisms responsible for the adaptation to acute hypoxia might be of great added value to improve the understanding of causes and consequences of hypoxia in critical illness. Also the mechanism on how GR is able to inhibit HIF mediated effects in AMS, at the level of HIF itself or more downstream on HIF triggered inflammatory pathways might also be important in critically ill and septic patients and lead to the identification of new therapeutic targets. 


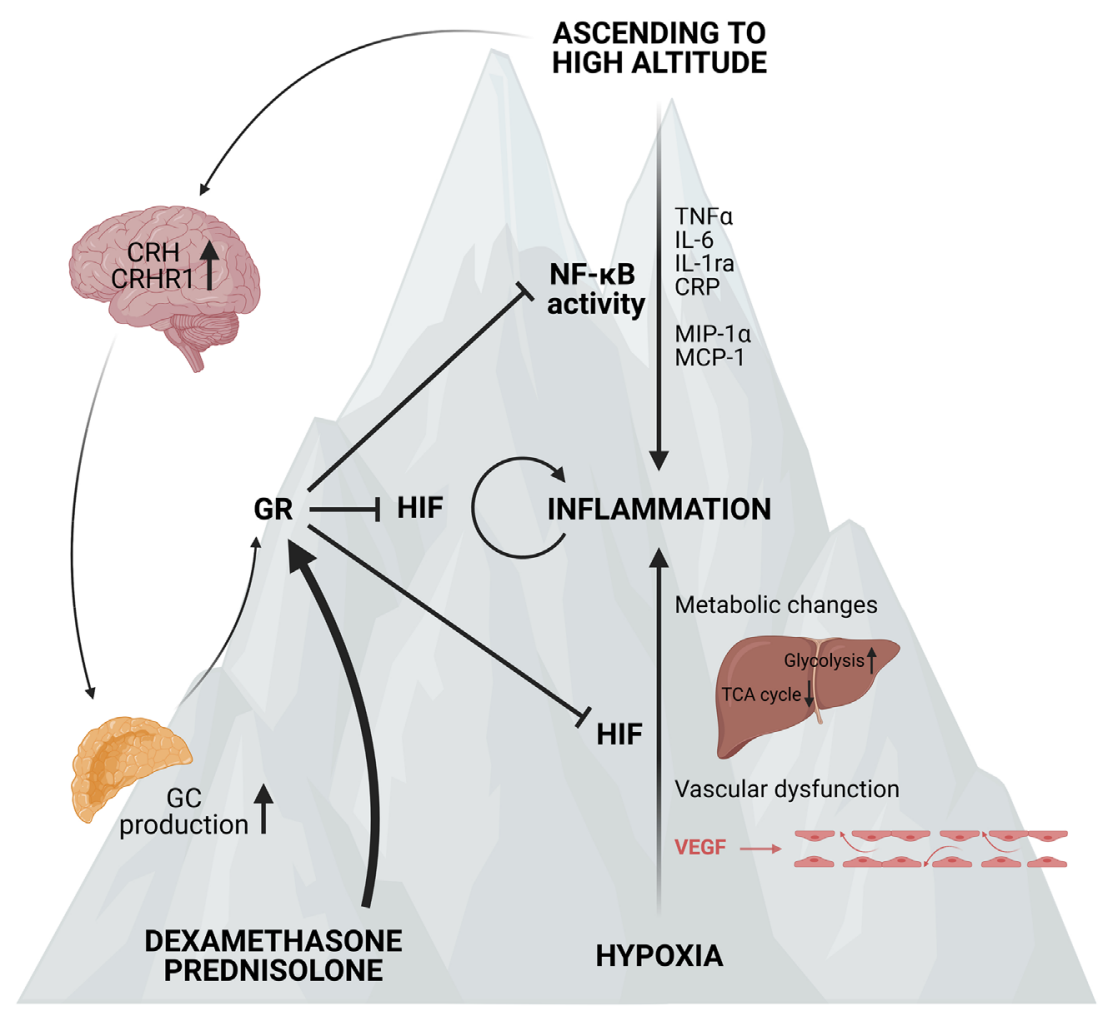

FIGURE 7 | Acute mountain sickness (AMS) and the prophylactic effect of synthetic GCs. Ascending to high altitude can lead to the development of AMS. This is characterized by elevated NF-kB expression and higher levels of po-inflammatory markers such as TNF $\alpha$, IL-6, IL-1ra, CRP and chemokines like MCP-1 and MIP-1 $\alpha$. Next to the inflammatory response, the expression of $\mathrm{CRH}$ and its receptor $\mathrm{CRHR} 1$ in the hypothalamus is also elevated, leading to increased GC production by the adrenal glands and stimulation of the GR. When ascending to high altitude, the hypoxic response is also characterized by metabolic changes and vascular dysfunction induced by the vascular endothelial growth factor (VEGF) contributing to the inflammatory response. When pre-treated with synthetic GCs such as dexamethasone and prednisolone, the GR is stimulated and the NF- $\mathrm{kB}$ and HIF mediated responses are inhibited and the symptoms of AMS are reduced. Figures created with Biorender.

\section{OXYGEN DEPRIVATION DURING BIRTH AND THE ROLE OF GCs}

Hypoxia during the period before and during parturition, and also after birth is one of the most common causes of neonatal morbidity followed by admission to the intensive care unit and neonatal mortality. Causes of foetal hypoxia might include unhealthy behaviour and the presence of chronic diseases in pregnant women (e.g. cardiovascular diseases, diabetes and anaemia). Also impairment of the foetal-placental barrier and exposure to harmful environments can lead to foetal hypoxia $(142,143)$. Postnatal hypoxia can appear from birth until days to weeks after parturition and is caused by a variety of cardiovascular and pulmonary disorders e.g. lack of lung development following preterm birth or patent ductus arteriosus in which the ductus arteriosus fails to close after birth $(144,145)$. Hypoxia in the premature neonate is generally associated with a harmful conditions requiring mechanical ventilation and oxygen therapy, GCs and other supplementary therapies $(146,147)$. The adaptation of neonates to hypoxia requires a coordinated physiological response, which includes an increase in the release of GCs, but not aldosterone, from the adrenal cortex. This implies a zone- specific adaptation of the adrenal glands to hypoxia (148). In vitro studies have shown that adrenal cells isolated from hypoxic neonatal rats display increased steroidogenesis due to hypoxia-induced changes to the steroidogenic enzyme activity rather than an alterations in the expression of steroidogenic enzymes (149). This is in contrast with adult rodents where hypoxia leads to a decreased expression of steroidogenic enzymes (150) and HIF1 $\alpha$ is a central regulator of steroidogenesis (98).

\section{The Effect of Neonatal Hypoxia on the Activity of the HPA Axis}

To gain further insights into the effect of neonatal hypoxia on the HPA axis, Raff et al. exposed suckling rats to hypoxia from birth until 5-7 days of age. This results into increased basal GC levels while no differences in endogenous plasma ACTH levels are detected $(89,90)$. The augmentation in steroidogenesis appears to be partly mediated by an increase in intracellular controllers of mitochondrial cholesterol transport, namely the steroidogenic acute regulatory (StAR) and peripheral-type benzodiazepine receptor (PBR) proteins (89). Since GCs induce a negative feedback loop at the level of the hypothalamus and pituitary, most likely when the hypothalamus is exposed to a direct stimulus e.g. ether vapours, this 
increased GC levels will inhibit the ACTH response to this stimulus (90). Also when perinatal hypoxia is induced in pregnant dams, maintaining them in a hypoxic environment during parturition and maintaining pups in hypoxia until 2 weeks of age, the GC response to an acute stressor in adult rats is significantly higher. This enhanced GC response is linked to higher $\mathrm{CRH}$ mRNA levels in the paraventricular nucleus (PVN) of the hypothalamic cells (151). The exposure of pregnant rats to hypoxia during the gestational period important for the maturation of the hippocampus induces long-term impairments in the GC system of the progeny. The exposure of pregnant females to adverse effects such as hypoxia causes an excess of GCs produced and a weakened negative feedback control of the HPA axis activity, resulting in higher baseline GC levels (152). This is associated with decreased nuclear GR protein levels (153) and reduced expression of GR dependent genes in the hippocampus of newborn rats. Additionally, the exposure to hypoxia during foetal development causes an agerelated depletion of GR in the liver and is accompanied with a reduced efficacy of GC mediated processes such as the inability to maintain normal glucose levels by the liver (152).

\section{The Effects of GCs on Hypoxia-Ischemia Induced Neonatal Brain Injury}

Next to GR, it is clear that HIF1 $\alpha$ also plays a role in hypoxiaischemia (HI) induced neonatal brain injury. The inhibition of HIF1 $\alpha$ after a HI-induced injury results in neuroprotective effects by maintaining the blood-brain-barrier (BBB) integrity and reducing brain edema (154). On the contrary, when HIF1 $\alpha$ is induced in a severe neonatal HI model, the BBB permeability is attenuated by the inhibition of VEGFA (91). It is clear that the exposure to perinatal and postnatal hypoxia causes a higher GC response, however a more detailed understanding of the mechanism and the timing of the HPA axis response to acute hypoxia remains to be further elucidated. Furthermore, the exposure to hypoxia during the perinatal period does have long-term pathophysiological effects that persist until adulthood. Next to that, a role of GR and HIF1 $\alpha$ in HI-induced brain injury in neonates is obvious. It is likely that GR and HIF1 $\alpha$ influence the adaptive response to a HIinduced insult thereby causing metabolic, apoptotic and inflammatory differences.

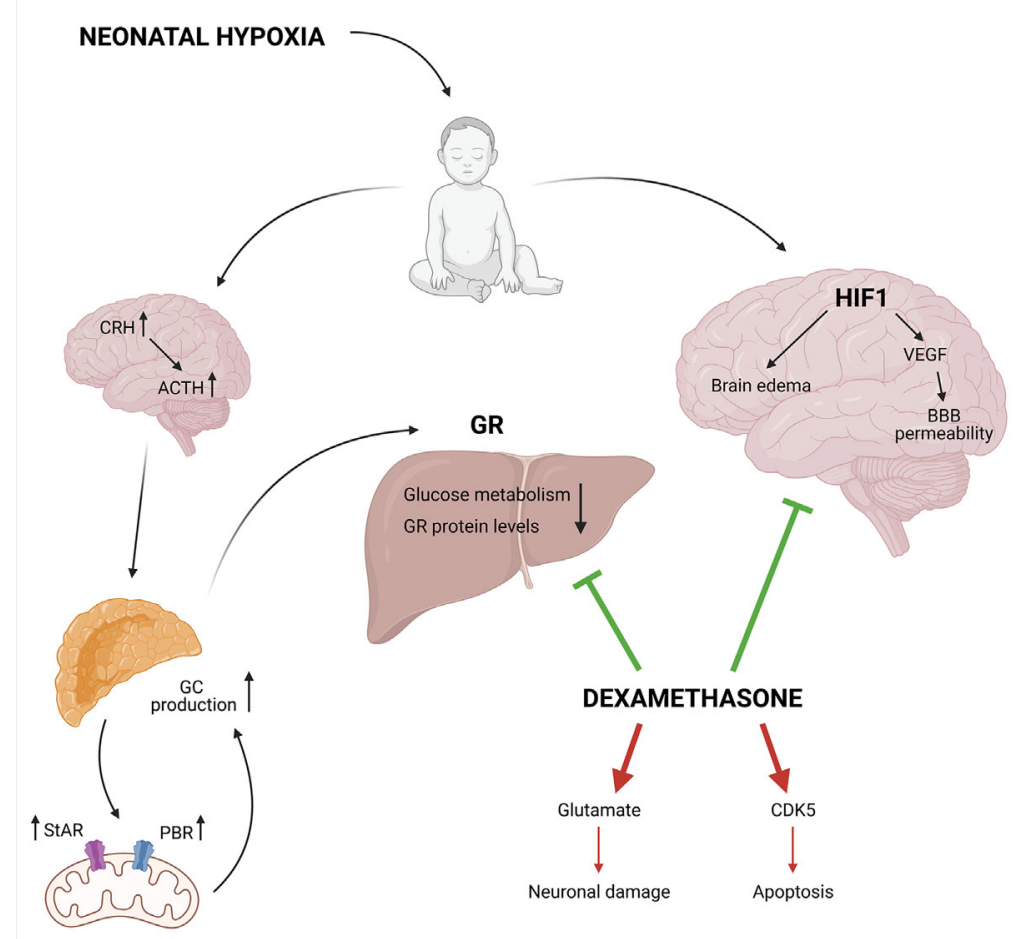

FIGURE 8 | The neuroprotective and neurotoxic effects of synthetic GCs during neonatal hypoxia. Neonatal hypoxia activates the HPA axis leading to increased GC production, partly mediated by a higher StAR and PBR expression involved in the mitochondrial cholesterol transport. This leads to decreased GR protein levels and reduced glucose metabolism. On the other hand, HIF1 is involved in the hypoxia-ischemia induced brain injury via the induction of VEGF and increases blood-brain barrier permeability in combination with brain edema. Neuroprotective effects can be induced by DEX via the inhibition of HIF1 mediated brain injury and the inhibition of the GR mediated effects in the liver. Next to the neuroprotective effects, DEX also has neurotoxic effects. It can lead to increased glutamate levels and CDK5 expression causing neuronal damage and apoptosis, respectively. Figures created with Biorender. 


\section{Neuroprotective Mechanisms of GCs}

Perinatal hypoxia results in a significant increase in hypoxiainduced brain infarct size in neonates. The question remains whether treatment of neonatal HI-induced brain injury with exogenous GCs like DEX provide neuroprotective or neurotoxic effects. It is shown by Tuor et al. that DEX-mediated alterations in metabolism have a protective effect against neonatal HI-induced brain damage $(92,93)$. Additionally, the inflammatory response in $\mathrm{HI}$ injury is attenuated when neonates are treated with GCs by significantly reducing TNF $\alpha$ production (155). GCs also provide neuroprotective effects by inhibiting cleaved caspase-3. Hence, treatment of neonates with exogenous GCs affects downstream apoptotic pathways and decreased neuronal cell death in the brain injury. Furthermore, DEX also exerts neuroprotective effects by activating phosphorylated Akt, which is important in neuronal prosurvival signals (156). In general, the protective effects of DEX focuses more on the mechanisms that cause damage to neuronal cells rather than decreasing ROS $(92,157)$. When DEX is administered via an intracerebroventricular (ICV) injection prior to hypoxia-ischemia (HI), a concentration-dependent neuroprotective effect of DEX on HI-induced brain injury is present in which the VEGF pathway is partially involved (158). This suggests a direct, local neuroprotective effect of the activation of GR in the neonatal brain.

\section{Neurotoxic Mechanisms of GCs}

However, when exposed to foetal hypoxia the neuroprotective effect of DEX in the neonatal brain is abrogated, most likely due to the downregulation in GR protein levels in the developing brain. This implies a role for GR in the increased vulnerability to HI-induced brain injury in the neonate due to foetal stress (153). The dosing and duration of GC treatment determines the neuroprotective or neurotoxic outcomes. For example, chronic exposure to GCs before $\mathrm{HI}$-induced brain injury results in exacerbated neuronal cell death and white-matter injure (159). GCs also cause an accumulation of glutamate in the brain

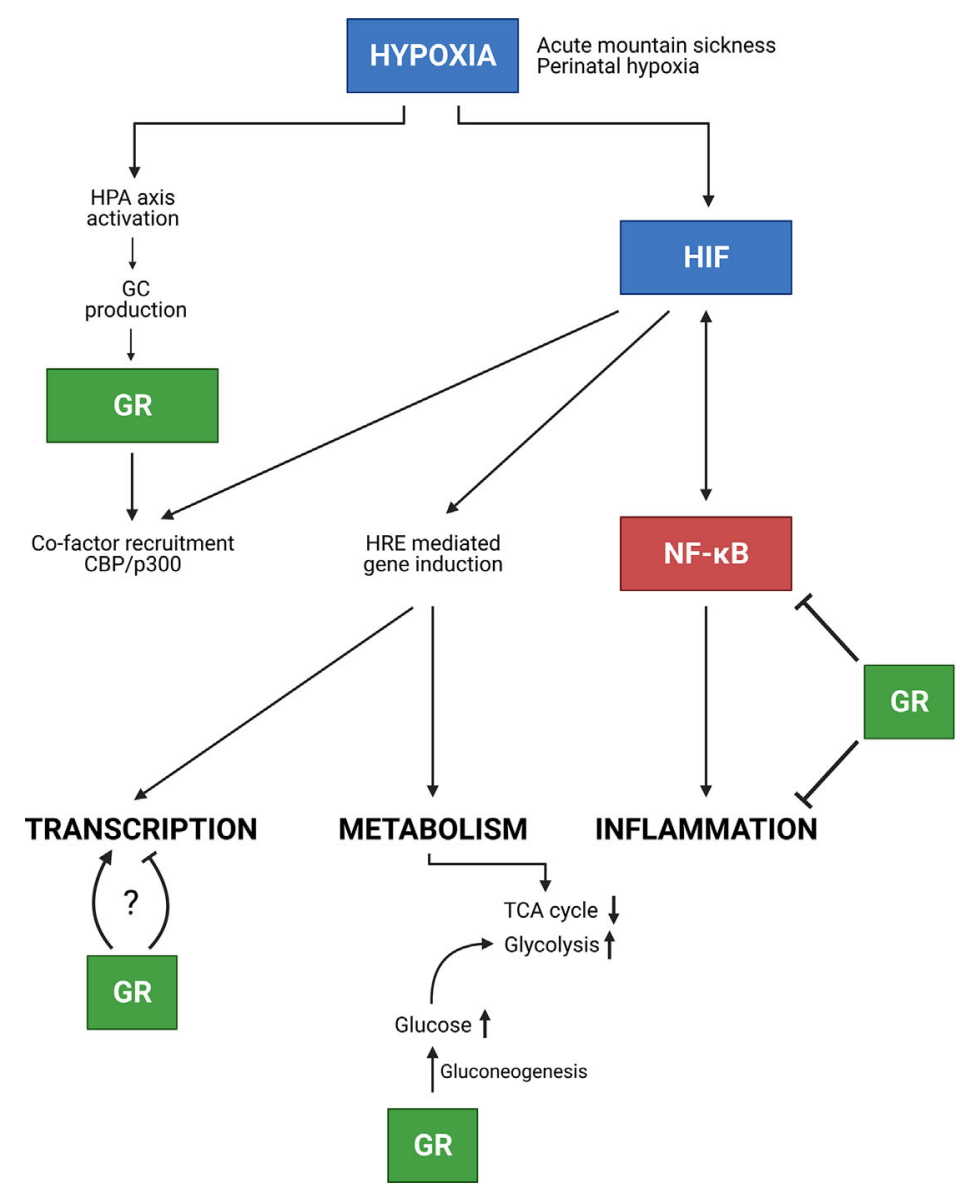

FIGURE 9 | Conclusion. In the presence of hypoxia e.g. due to AMS or neonatal hypoxia, the HPA axis is activated thereby increasing GC production and GR mediated effects. Next to GR, HIF is involved in NF-kB inflammatory responses, in which these responses can be inhibited by GR. Furthermore, HIF mediated transcription is stimulated, but GR competes with HIF in the recruitment of co-factors e.g. CBP/p300. Whether GR stimulates or inhibits HIF mediated transcription requires further investigation. Finally, hypoxia also causes metabolic changes. The GR promotes gluconeogenesis thereby increasing glucose levels which will be used during glycolysis for appropriate energy levels in hypoxic conditions. Figures created with Biorender. 
thereby inducing cytotoxicity and neuronal damage, which contributes to the detrimental effects in neonatal brain injury (160). Also, GCs enhance apoptotic cell death via overexpression of cyclin-dependent kinase 5 (CDK5), which is an important kinase for cell cycle regulation (Figure 8) (161).

In conclusion, evidence is provided that treatment of neonatal HI-induced brain injury with DEX can be either neuroprotective or neurotoxic $(94,95)$. In most cases, when DEX is administered systematically and chronically, neurotoxicity remains present, but when DEX is administered directly into the brain, it becomes neuroprotective. The ability of GCs to suppress neuroinflammation caused by hypoxia is thus dependent on dosing, timing and duration after the initial injury.

\section{CONCLUSION}

The bidirectional crosstalk between GR and HIF is clearly highlighted based on the studies described above. In vitro studies have shown cell-type specific effects of exogenous GCs on hypoxia-dependent gene expression and HIF1 $\alpha$ activity upon hypoxia, which is associated with effects on the nuclear translocation and DNA binding of HIF. Conversely, hypoxia is also able to exert an effect on the GR mRNA and protein levels by influencing GR nuclear translocation or due to the binding of HIF1 to HREs present at the NR3C1 promotor. Only a few in vivo studies using zebrafish as a model organism have addressed the direct interaction between HIF and GR, thereby showing that HIF represses GR activity and its responsiveness to exogenous GCs. Moreover, HIF signalling reduces GC production by acting on POMC expression at the level of the hypothalamus. Further in vivo studies will be necessary to elucidate the precise crosstalk between these two complex signalling pathways.

GCs are known to be strong anti-inflammatory mediators. However, in this review, it is shown that hypoxia is able to affect these anti-inflammatory effects by influencing the DEX mediated suppression of pro-inflammatory cytokine production. On the contrary, hypoxia leads to higher GILZ levels in macrophages when exposed to an inflammatory stimulus to prevent overactivation of immune cells and overproduction of proinflammatory cytokines. This teaches us that a balance between GR and HIF mediated signalling is required upon inflammatory conditions and that it will be necessary to further investigate the

\section{REFERENCES}

1. de Guia RM, Herzig S. How do Glucocorticoids Regulate Lipid Metabolism? Adv Exp Med Biol (2015) 872:127-44. doi: 10.1007/978-1-4939-2895-8

2. Rose AJ, Herzig S. Metabolic Control Through Glucocorticoid Hormones: An Update. Mol Cell Endocrinol (2013) 380:65-78. doi: 10.1016/ j.mce.2013.03.007

3. Cruz-Topete D, Cidlowski JA. One Hormone, Two Actions: Anti- and ProInflammatory Effects of Glucocorticoids. Neuroimmunomodulation (2014) 22:20-32. doi: 10.1159/000362724

4. Fowden AL, Forhead AJ. Glucocorticoids as Regulatory Signals During Intrauterine Development. Exp Physiol (2015) 100:1477-87. doi: 10.1113/ EP085212 interplay between HIF and GR in disease models such as IMH, $\mathrm{PAH}$ and sepsis. Also the link with NF- $\mathrm{KB}$ signalling is of utmost importance (Figure 9). The exploration of possible mechanisms responsible for the adaptation to acute hypoxia might be of great added value to improve the understanding of causes and consequences of hypoxia in critical illness. Also the mechanism on how GR is able to inhibit HIF mediated effects in AMS, at the level of HIF itself or more downstream on HIF triggered inflammatory pathways might also be important in critically ill and septic patients and lead to the identification of new therapeutic targets.

Since hypoxia is one of the most common causes of morbidity and mortality in neonates, a more complete understanding of what is the mechanism behind these hypoxic conditions in neonates will be of great added value. It is necessary to find the ideal dose, timing and during of GC treatment so that neurotoxic effects of GCs can be eliminated. Considering the importance of HIF1 $\alpha$ during neural development, it could be relevant to further elucidate the use of PHD inhibitors or HIF stabilizers during neonatal hypoxia.

Overall, a clear interaction between HIF, GR and NF- $\kappa B$ is shown both in vitro and in vivo. It will be of importance to identify the role of specific HIF isoforms in several diseases and how this is connected with GR and/or NF- $\kappa \mathrm{B}$. Based on these results, specific targeting of certain HIF isoforms in inflammatory disease models could lead to the identification of new therapeutic targets.

\section{AUTHOR CONTRIBUTIONS}

TV wrote the draft, and RB and CL supervised, corrected, and finalized the paper. All authors contributed to the article and approved the submitted version.

\section{FUNDING}

Research in the lab of CL and RB is supported by the Research Council of Ghent University (GOA Program), the Research Foundation Flanders (FWO-Vlaanderen), the FWO Hercules program and Flanders Institute for Biotechnology (VIB).

5. Whirledge S, Cidlowski JA. Glucocorticoids and Reproduction: Traffic Control on the Road to Reproduction. Trends Endocrinol Metab (2017) 28:399-415. doi: 10.1016/j.tem.2017.02.005

6. Donatti TL, Koch VHK, Takayama L, Pereira RMR. Effects of Glucocorticoids on Growth and Bone Mineralization. J Pediatr (Rio J) (2011) 87:4-12. doi: 10.2223/JPED.2052

7. Tatomir A, Micu C, Crivii C. The Impact of Stress and Glucocorticoids on Memory. Clujul Med (2014) 87:3-6. doi: 10.15386/cjm.2014.8872.871.at1cm2

8. Joëls M. Impact of Glucocorticoids on Brain Function: Relevance for Mood Disorders. Psychoneuroendocrinology (2011) 36:406-14. doi: 10.1016/ j.psyneuen.2010.03.004

9. Walker BR. Glucocorticoids and Cardiovascular Disease. Eur J Endocrinol (2007) 157:545-59. doi: 10.1530/EJE-07-0455 
10. Miller WL. Androgen Synthesis in Adrenarche. Rev Endocr Metab Disord (2009) 10:3-17. doi: 10.1007/s11154-008-9102-4

11. Ahmed A, Schmidt C, Brunner T. Extra-Adrenal Glucocorticoid Synthesis in the Intestinal Mucosa: Between Immune Homeostasis and Immune Escape. Front Immunol (2019) 10:1438. doi: 10.3389/fimmu.2019.01438

12. Medzhitov R, Schneider DS, Soares MP. Disease Tolerance as a Defense Strategy. Science (2012) 335:936-41. doi: 10.1126/science.1214935

13. Spiga F, Walker JJ, Terry JR, Lightman SL. HPA Axis-Rhythms. Compr Physiol (2014) 4:1273-98. doi: 10.1002/cphy.c140003

14. Walker JJ, Spiga F, Gupta R, Zhao Z, Lightman SL, Terry JR. Rapid IntraAdrenal Feedback Regulation of Glucocorticoid Synthesis. J R Soc Interface (2015) 12:1-10. doi: 10.1098/rsif.2014.0875

15. Hammond GL. Plasma Steroid-Binding Proteins: Primary Gatekeepers of Steroid Hormone Action. J Endocrinol (2016) 230:R13-25. doi: 10.1530/ JOE-16-0070

16. Hammond GL, Smith CL, Paterson NAM, Sibbald WJ. A Role for Corticosteroid-Binding Globulin in Delivery of Cortisol to Activated Neutrophils. J Clin Endocrinol Metab (1990) 71:34-9. doi: 10.1210/jcem-71-1-34

17. Timmermans S, Souffriau J, Libert C. A General Introduction to Glucocorticoid Biology. Front Immunol (2019) 10:1545. doi: 10.3389/ fimmu.2019.01545

18. Cain DW, Cidlowski JA. Immune Regulation by Glucocorticoids. Nat Rev Immunol (2017) 17:233-47. doi: 10.1038/nri.2017.1

19. Vandevyver S, Dejager L, Libert C. Comprehensive Overview of the Structure and Regulation of the Glucocorticoid Receptor. Endocr Rev (2014) 35:671-93. doi: 10.1210/er.2014-1010

20. Kumar R, Volk DE, Li J, Lee JC, Gorenstein DG, Thompson EB. TATA Box Binding Protein Induces Structure in the Recombinant Glucocorticoid Receptor AF1 Domain. Proc Natl Acad Sci USA (2004) 101:16425-30. doi: 10.1073/pnas. 0407160101

21. Luisi BF, Xu WX, Otwinowski Z, Freedman LP, Yamamoto KR, Sigler PB. Crystallographic Analysis of the Interaction of the Glucocorticoid Receptor With DNA. Nature (1991) 352:497-505. doi: 10.1038/352497a0

22. Bledsoe RK, Montana VG, Stanley TB, Delves CJ, Apolito CJ, McKee DD, et al. Crystal Structure of the Glucocorticoid Receptor Ligand Binding Domain Reveals a Novel Mode of Receptor Dimerization and Coactivator Recognition. Cell (2002) 110:93-105. doi: 10.1016/S0092-8674(02)00817-6

23. Tang Y, Getzenberg RH, Vietmeier BN, Stallcup MR, Eggert M, Renkawitz $\mathrm{R}$, et al. The DNA-Binding and $\tau 2$ Transactivation Domains of the Rat Glucocorticoid Receptor Constitute a Nuclear Matrix-Targeting Signal. Mol Endocrinol (1998) 12:1420-31. doi: 10.1210/mend.12.9.0169

24. Vandevyver S, Dejager L, Libert C. On the Trail of the Glucocorticoid Receptor: Into the Nucleus and Back. Traffic (2012) 13:364-74. doi: 10.1111/ j.1600-0854.2011.01288.x

25. Vandewalle J, Luypaert A, Bosscher K, Libert C. Therapeutic Mechanisms of Glucocorticoids. Trends Endocrinol Metab (2018) 29:42-54. doi: 10.1016/ j.tem.2017.10.010

26. Diamond MI, Miner JN, Yoshinaga SK, Yamamoto KY. Transcription Factor Interactions: Selectors of Positive or Negative Regulation From a Single DNA Element. Science (1990) 249:1266-72. doi: 10.1126/science.2119054

27. Hudson WH, Youn C, Ortlund EA. The Structural Basis of Direct Glucocorticoid-Mediated Transrepression. Nat Struct Mol Biol (2013) 20:53-8. doi: $10.1038 / \mathrm{nsmb} .2456$

28. Lim H, Uhlenhaut $\mathrm{NH}$, Rauch $\mathrm{A}$, Weiner J, Hubner S, Hubner N, et al. Genomic Redistribution of GR Monomers and Dimers Mediates Transcription Response to Exogenous Ligand. Genome Res (2014) 25:83644. doi: 10.1101/gr.188581.114.10

29. Ratman D, Vanden Berghe W, Dejager L, Libert C, Tavernier J, Beck IM, et al. How Glucocorticoid Receptors Modulate the Activity of Other Transcription Factors: A Scope Beyond Tethering. Mol Cell Endocrinol (2013) 380:41-54. doi: 10.1016/j.mce.2012.12.014

30. Weikum ER, De Vera IMS, Nwachukwu JC, Hudson WH, Nettles KW, Kojetin DJ, et al. Tethering Not Required: The Glucocorticoid Receptor Binds Directly to Activator Protein-1 Recognition Motifs to Repress Inflammatory Genes. Nucleic Acids Res (2017) 45:8596-608. doi: 10.1093/ nar/gkx509

31. Sheppard KA, Phelps KM, Williams AJ, Thanos D, Glass CK, Rosenfeld MG, et al. Nuclear Integration of Glucocorticoid Receptor and Nuclear Factor- $\mathrm{Kb}$
Signaling by CREB-binding Protein and Steroid Receptor Coactivator-1. J Biol Chem (1998) 273:29291-4. doi: 10.1074/jbc.273.45.29291

32. Kino T, Chrousos GP. Tumor Necrosis Factor $\alpha$ Receptor- and FasAssociated FLASH Inhibit Transcriptional Activity of the Glucocorticoid Receptor by Binding to and Interfering With Its Interaction With p160 Type Nuclear Receptor Coactivators. J Biol Chem (2003) 278:3023-9. doi: 10.1074/ jbc.M209234200

33. Scheinman RI, Gualberto A, Jewell CM, Cidlowski JA, Baldwin AS Characterization of Mechanisms Involved in Transrepression of NF-kb by Activated Glucocorticoid Receptors. Mol Cell Biol (1995) 15:943-53. doi: $10.1128 / \mathrm{mcb} .15 .2 .943$

34. Song IH, Buttgereit F. Non-Genomic Glucocorticoid Effects to Provide the Basis for New Drug Developments. Mol Cell Endocrinol (2006) 246:142-6. doi: 10.1016/j.mce.2005.11.012

35. Nakayama K, Kataoka N. Regulation of Gene Expression Under Hypoxic Conditions. Int J Mol Sci (2019) 20:1-15. doi: 10.3390/ijms20133278

36. Hubbi ME, Semenza GL. Regulation of Cell Proliferation by HypoxiaInducible Factors. Am J Physiol - Cell Physiol (2015) 309:C775-82. doi: 10.1152/ajpcell.00279.2015

37. Denko NC. Hypoxia, HIF and Metabolism in the Solid Tumour. Nat Rev Cancer (2008) 8:705-13. doi: 10.1038/nrc2468

38. Krock BL, Skuli N, Simon MC. Hypoxia-Induced Angiogenesis: Good and Evil. Genes Cancer (2011) 2:1117-33. doi: 10.1177/1947601911423654

39. Prabhakar NR, Semenza GL. Oxygen Sensing and Homeostasis. Physiology (2015) 30:340-8. doi: 10.1152/physiol.00022.2015

40. Bleymehl K, Pérez-Gómez A, Omura M, Moreno-Pérez A, Macías D, Bai Z, et al. A Sensor for Low Environmental Oxygen in the Mouse Main Olfactory Epithelium. Neuron (2016) 92:1196-203. doi: 10.1016/j.neuron.2016.11.001

41. Kaelin WG, Ratcliffe PJ. Oxygen Sensing by Metazoans: The Central Role of the HIF Hydroxylase Pathway. Mol Cell (2008) 30(4):393-402. doi: 10.1016/ j.molcel.2008.04.009

42. Chandel NS, Maltepe E, Goldwasser E, Mathieu CE, Simon MC SP. Mitochondrial Reactive Oxygen Species Trigger Hypoxia-Induced Transcription. Proc Natl Acad Sci USA (1998) 95:11715-20. doi: 10.1073/ pnas.95.20.11715

43. Guzy RD, Schumacker PT. Oxygen Sensing by Mitochondria At Complex III: The Paradox of Increased Reactive Oxygen Species During Hypoxia. Exp Physiol (2006) 91:807-19. doi: 10.1113/expphysiol.2006.033506

44. Song D, Li LS, Heaton-Johnson KJ, Arsenault PR, Master SR, Lee FS. Prolyl Hydroxylase Domain Protein 2 (PHD2) Binds a Pro-Xaa-Leu-Glu Motif, Linking it to the Heat Shock Protein 90 Pathway. J Biol Chem (2013) 288:9662-74. doi: $10.1074 /$ jbc.M112.440552

45. Masson N, Singleton RS, Sekirnik R, Trudgian DC, Ambrose LJ, Miranda MX, et al. The FIH Hydroxylase Is a Cellular Peroxide Sensor That Modulates HIF Transcriptional Activity. EMBO Rep (2012) 13:251-7. doi: 10.1038/embor.2012.9

46. Rhee SG, Woo HA, Kil IS, Bae SH. Peroxiredoxin Functions as a Peroxidase and a Regulator and Sensor of Local Peroxides. J Biol Chem (2012) 287:4403-10. doi: 10.1074/jbc.R111.283432

47. Cockman ME, Lippl K, Tian YM, Pegg HB, Figg WD, Abboud MI, et al. Lack of Activity of Recombinant HIF Prolyl Hydroxylases (Phds) on Reported Non-HIF Substrates. Elife (2019) 8:1-27. doi: 10.7554/eLife.46490

48. Dai Z, Li M, Wharton J, Zhu MM, Zhao YY. Prolyl-4 Hydroxylase 2 (PHD2) Deficiency in Endothelial Cells and Hematopoietic Cells Induces Obliterative Vascular Remodeling and Severe Pulmonary Arterial Hypertension in Mice and Humans Through Hypoxia-Inducible Factor2a. Circulation (2016) 133:2447-58. doi: 10.1161/CIRCULATIONAHA.116. 021494

49. Franke K, Gassmann M, Wielockx B. Erythrocytosis: The HIF Pathway in Control. Blood (2013) 122:1122-8. doi: 10.1182/blood-2013-01-478065

50. Wiesener MS, Jürgensen JS, Rosenberger C, Scholze CK, Hörstrup JH, Warnecke C, et al. Widespread Hypoxia-Inducible Expression of HIF2alpha in Distinct Cell Populations of Different Organs. FASEB J (2003) 17:271-3. doi: 10.1096/fj.02-0445fje

51. Korovina I, Neuwirth A, Sprott D, Weber S, Pasha SPBS, Gercken B, et al. Hematopoietic Hypoxia-Inducible Factor $2 \alpha$ Deficiency Ameliorates Pathological Retinal Neovascularization Via Modulation of Endothelial Cell Apoptosis. FASEB J (2019) 33:1758-70. doi: 10.1096/ff.201800430R 
52. García-Martín R, Alexaki V, Qin N, Rubín de Celis M, Economopoulou M, Ziogas A, et al. Exacerbates Obesity-Induced Brown Adipose Tissue Dysfunction and. Mol (2016) 36:376-93. doi: 10.1128/MCB.0043015.Address

53. Berra E, Benizri E, Volmat V, Ginouve A, Roux D, Pouysségur J. HIF ProlylHydroxylase 2 Is the Key Oxygen Sensor Setting Low Steady-State Levels of HIF-1 a in Normoxia. EMBO J (2003) 22:4082-90. doi: 10.1093/emboj/ cdg392

54. Appelhoff RJ, Tian Y, Raval RR, Turley H, Harris AL, Pugh CW, et al. Differential Function of the Prolyl Hydroxylases PHD1, PHD2, and PHD3 in the Regulation of Hypoxia-Inducible Factor. J Biol Chem (2004) 279:38458-65. doi: 10.1074/jbc.M406026200

55. Webb JD, Coleman ML, Pugh CW. Hypoxia, Hypoxia-Inducible Factors (HIF), HIF Hydroxylases and Oxygen Sensing. Cell Mol Life Sci (2009) 1:3539-54. doi: 10.1007/s00018-009-0147-7

56. Takeda K, Ho VC, Takeda H, Duan L-J, Nagy A, Fong G-H. Placental But Not Heart Defects Are Associated With Elevated Hypoxia-Inducible Factor $\alpha$ Levels in Mice Lacking Prolyl Hydroxylase Domain Protein 2. Mol Cell Biol (2006) 26:8336-46. doi: 10.1128/mcb.00425-06

57. Minamishima YA, Moslehi J, Bardeesy N, Cullen D, Bronson RT, Kaelin WG. Somatic Inactivation of the PHD2 Prolyl Hydroxylase Causes Polycythemia and Congestive Heart Failure. Blood (2008) 111:3236-44. doi: 10.1182/blood-2007-10-117812

58. Aragonés J, Schneider M, Van Geyte K, Fraisl P, Dresselaers T, Mazzone M, et al. Deficiency or Inhibition of Oxygen Sensor Phd1 Induces Hypoxia Tolerance by Reprogramming Basal Metabolism. Nat Genet (2008) 40:17080. doi: 10.1038/ng.2007.62

59. Bishop T, Gallagher D, Pascual A, Lygate CA, de Bono JP, Nicholls LG, et al. Abnormal Sympathoadrenal Development and Systemic Hypotension in PHD3-/- Mice. Mol Cell Biol (2008) 28:3386-400. doi: 10.1128/mcb.02041-07

60. Bonello S, Zähringer C, BelAiba RS, Djordjevic T, Hess J, Michiels C, et al. Reactive Oxygen Species Activate the HIF-1 $\alpha$ Promoter Via a Functional Nfkb Site. Arterioscler Thromb Vasc Biol (2007) 27:755-61. doi: 10.1161/ 01.ATV.0000258979.92828.bc

61. Kodama T, Shimizu N, Yoshikawa N, Makino Y, Ouchida R, Okamoto K, et al. Role of the Glucocorticoid Receptor for Regulation of Hypoxiadependent Gene Expression*. J Biol Chem (2003) 278:33384-91. doi: 10.1074/jbc.M302581200

62. Leonard MO, Godson C, Brady HR, Taylor CT. Potentiation of Glucocorticoid Activity in Hypoxia Through Induction of the Glucocorticoid Receptor. J Immunol (2005) 174:2250-7. doi: 10.4049/ jimmunol.174.4.2250

63. Zhang C, Qiang Q, Jiang Y, Hu L, Ding X, Lu Y, et al. Effects of Hypoxia Inducible Factor- $1 \alpha$ on Apoptotic Inhibition and Glucocorticoid Receptor Downregulation by Dexamethasone in AtT-20 Cells. BMC Endocr Disord (2015) 15:1-9. doi: 10.1186/s12902-015-0017-2

64. Wagner AE, Huck G, Stiehl DP, Jelkmann W, Hellwig-Bürgel T. Dexamethasone Impairs Hypoxia-Inducible Factor-1 Function. Biochem Biophys Res Commun (2008) 372:336-40. doi: 10.1016/j.bbrc. 2008.05.061

65. Tuder RM, Yun JH, Bhunia A, Fijalkowska I. Hypoxia and Chronic Lung Disease. J Mol Med (2007) 85:1317-24. doi: 10.1007/s00109-007-0280-4

66. Huang Y, Zhao JJ, Lv YY, Ding PS, Liu RY. Hypoxia Down-Regulates Glucocorticoid Receptor Alpha and Attenuates the Anti-Inflammatory Actions of Dexamethasone in Human Alveolar Epithelial A549 Cells. Life Sci (2009) 85:107-12. doi: 10.1016/j.lfs.2009.04.026

67. Zhang P, Fang L, Wu HM, Ding P, Shen QY, Liu R. Down-Regulation of Gro Expression and Inhibition of Its Nuclear Translocation by Hypoxia. Life Sci (2016) 146:92-9. doi: 10.1016/j.lfs.2015.12.059

68. Trousson A, Grenier J, Fonte C, Massaad-Massade L, Schumacher M, Massaad C. Recruitment of the p160 Coactivators by the Glucocorticoid Receptor: Dependence on the Promoter Context and Cell Type But Not Hypoxic Conditions. J Steroid Biochem Mol Biol (2007) 104:305-11. doi: 10.1016/j.jsbmb.2007.03.018

69. Charron CE, Chou PC, Coutts DJC, Kumar V, To M, Akashi K, et al. HypoxiaInducible Factor $1 \alpha$ Induces Corticosteroid-Insensitive Inflammation Via Reduction of Histone Deacetylase-2 Transcription. J Biol Chem (2009) 284:36047-54. doi: 10.1074/jbc.M109.025387
70. Bosco MC, Puppo M, Blengio F, Fraone T, Cappello P, Giovarelli M, et al. Monocytes and Dendritic Cells in a Hypoxic Environment: Spotlights on Chemotaxis and Migration. Immunobiology (2008) 213:733-49. doi: 10.1016/j.imbio.2008.07.031

71. Safronova O, Pluemsampant S, Nakahama Ki, Morita I. Regulation of Chemokine Gene Expression by Hypoxia Via Cooperative Activation of NF- $\mathrm{kb}$ and Histone Deacetylase. Int J Biochem Cell Biol (2009) 41:2270-80. doi: 10.1016/j.biocel.2009.05.003

72. Lewis C, Murdoch C. Macrophage Responses to Hypoxia: Implications for Tumor Progression and Anti-Cancer Therapies. Am J Pathol (2005) 167:627-35. doi: 10.1016/S0002-9440(10)62038-X

73. Hempel SL, Monick MM, Hunninghake GW. Effect of Hypoxia on Release of IL-1 and TNF by Human Alveolar Macrophages. Am J Respir Cell Mol Biol (1996) 14:170-6. doi: 10.1165/ajrcmb.14.2.8630267

74. D’Adamio F, Zollo O, Moraca R, Ayroldi E, Bruscoli S, Bartoli A, et al. A New Dexamethasone-Induced Gene of the Leucine Zipper Family Protects T Lymphocytes From TCR/CD3-activated Cell Death. Immunity (1997) 7:803-12. doi: 10.1016/S1074-7613(00)80398-2

75. Hamdi H, Bigorgne A, Naveau S, Balian A, Bouchet-Delbos L, CassardDoulcier AM, et al. Glucocorticoid-Induced Leucine Zipper: A Key Protein in the Sensitization of Monocytes to Lipopolysaccharide in Alcoholic Hepatitis. Hepatology (2007) 46:1986-92. doi: 10.1002/hep.21880

76. Wang Y, Ma Y-Y, Song X-L, Cai H-Y, Chen J-C, Song L-N, et al. Upregulations of Glucocorticoid-Induced Leucine Zipper by Hypoxia and Glucocorticoid Inhibit Proinflammatory Cytokines Under Hypoxic Conditions in Macrophages. J Immunol (2012) 188:222-9. doi: 10.4049/ jimmunol.1002958

77. Lim W, Park C, Shim MK, Lee YH, Lee YM, Lee Y. Glucocorticoids Suppress Hypoxia-Induced COX-2 and Hypoxia Inducible Factor- $1 \alpha$ Expression Through the Induction of Glucocorticoid-Induced Leucine Zipper. $\mathrm{Br} J$ Pharmacol (2014) 171:735-45. doi: 10.1111/bph.12491

78. Xue L, Greisler HP. Angiogenic Effect of Fibroblast Growth Factor-1 and Vascular Endothelial Growth Factor and Their Synergism in a Novel In Vitro Quantitative Fibrin-Based 3-Dimensional Angiogenesis System. Surgery (2002) 132:259-67. doi: 10.1067/msy.2002.125720

79. Ke X, Chen C, Song Y, Cai Q, Li J, Tang Y, et al. Hypoxia Modifies the Polarization of Macrophages and Their Inflammatory Microenvironment, and Inhibits Malignant Behavior in Cancer Cells. Oncol Lett (2019) 18:58718. doi: 10.3892/ol.2019.10956

80. Liu B, Goodwin JE. The Effect of Glucocorticoids on Angiogenesis in the Treatment of Solid Tumors. J Cell Signal (2020) 1:42-9. doi: 10.33696/ Signaling.1.011

81. Vettori A, Greenald D, Wilson GK, Peron M, Facchinello N, Markham E et al. Glucocorticoids Promote Von Hippel Lindau Degradation and Hif- $1 \alpha$ Stabilization. Proc Natl Acad Sci (2017) 114:9948-53. doi: 10.1073/ pnas. 1705338114

82. Marchi D, Santhakumar K, Markham E, Li N, Storbeck KH, Krone N, et al Bidirectional Crosstalk Between Hypoxia-Inducible Factor and Glucocorticoid Signalling in Zebrafish Larvae. PloS Genet (2020) 16:1-28 doi: 10.1371/journal.pgen.1008757

83. Rock PB, Johnson TS, Larsen RF, Fulco CS, Trad LA, Cymerman A. Dexamethasone as Prophylaxis for Acute Mountain Sickness. Effect of Dose Level. Chest (1989) 95:568-73. doi: 10.1378/chest.95.3.568

84. Johnson T, Rock P, Fulco C, Trad L, Spark R, Maher J. Prevention of Acute Mountain Sickness by Dexamethasone. N Engl J Med (1984) 310:683-6. doi: 10.1056/NEJM198403153101103

85. Basu M, Sawhney RC, Kumar S, Pal K, Prasad R, Selvamurthy W Glucocorticoids as Prophylaxis Against Acute Mountain Sickness. Clin Endocrinol (Oxf) (2002) 57:761-7. doi: 10.1046/j.1365-2265.2002.01664.x

86. Basu M, Sawhney RC, Kumar S, Pal K, Prasad R, Selvamurthy W. Hypothalamic-Pituitary-Adrenal Axis Following Glucocorticoid Prophylaxis Against Acute Mountain Sickness. Horm Metab Res (2002) 34:318-24. doi: 10.1055/s-2002-33260

87. Kitsteiner JM, Whitworth JD, Nashelsky J. Preventing Acute Mountain Sickness. Am Fam Physician (2011) 84:398-400.

88. Zheng CR, Chen GZ, Yu J, Qin J, Song P, Bian SZ, et al. Inhaled Budesonide and Oral Dexamethasone Prevent Acute Mountain Sickness. Am J Med (2014) 127:1001-9. doi: 10.1016/j.amjmed.2014.04.012 
89. Raff H, Hong JJ, Oaks MK, Widmaier EP. Adrenocortical Responses to ACTH in Neonatal Rats: Effect of Hypoxia From Birth on Corticosterone, StAR, and PBR. Am J Physiol - Regul Integr Comp Physiol (2003) 284:78-85. doi: 10.1152/ajpregu.00501.2002

90. Raff H, Jacobson L, Cullinan WE. Elevated Corticosterone and Inhibition of ACTH Responses to CRH and Ether in the Neonatal Rat: Effect of Hypoxia From Birth. Am J Physiol - Regul Integr Comp Physiol (2003) 285:1224-30. doi: 10.1152/ajpregu.00259.2003

91. Shi X, Doycheva DM, Xu L, Tang J, Yan M, Zhang JH. Sestrin2 Induced by Hypoxia Inducible Factor 1 Alpha Protects the Blood-Brain Barrier Via Inhibiting VEGF After Severe Hypoxic-Ischemic Injury in Neonatal Rats. Neurobiol Dis (2016) 95:111-21. doi: 10.1016/j.nbd.2016.07.016.Sestrin2

92. Tuor UI, Simone CS, Arellano R, Tanswell K, Post M. Glucocorticoid Prevention of Neonatal Hypoxic-Ischemic Damage: Role of Hyperglycemia and Antioxidant Enzymes. Brain Res (1993) 604:165-72. doi: 10.1016/00068993(93)90364-S

93. Tuor UI, Yager JY, Bascaramurty S, Del Bigio MR. Dexamethasone Prevents Hypoxia / Ischemia-Induced Reductions in Cerebral Glucose Utilization and High-Energy Phosphate Metabolites in Immature Brain. J Neurochem (1997) 69:1954-63. doi: 10.1046/j.1471-4159.1997.69051954.x

94. Harding B, Conception K, Li Y, Zhang L. Glucocorticoids Protect Neonatal Rat Brain in Model of Hypoxic-Ischemic Encephalopathy (HIE). Int J Mol Sci (2017) 18:1-12. doi: 10.3390/ijms18010017

95. Gonzalez-Rodriguez PJ, Li Y, Martinez F, Zhang L. Dexamethasone Protects Neonatal Hypoxic-Ischemic Brain Injury Via L-PGDS-Dependent Pgd2DP1-pERK Signaling Pathway. PloS One (2014) 9:1-14. doi: 10.1371/ journal.pone. 0114470

96. Ziv L, Muto A, Schoonheim PJ, Meijsing SH, Strasser D, Ingraham HA, et al. An Affective Disorder in Zebrafish With Mutation of the Glucocorticoid Receptor. Mol Psychiatry (2013) 18:681-91. doi: 10.1038/mp.2012.64

97. Yang N, Berry A, Sauer C, Baxter M, Donaldson IJ, Forbes K, et al. Hypoxia Regulates GR Function Through Multiple Mechanisms Involving microRNAs 103 and 107. Mol Cell Endocrinol (2020) 518:111007. doi: 10.1016/j.mce.2020.111007

98. Watts D, Stein J, Meneses A, Bechmann N, Neuwirth A, Kaden D, et al. Hif1 $\alpha$ Is an Essential Regulator of Steroidogenesis in the Adrenal Gland. Cell Mol Life Sci (2021) 78(7):3577-90. doi: 10.1101/2020.07.08.191783

99. Lu Y, Liu H, Bi Y, Yang H, Li Y, Wang J, et al. Glucocorticoid Receptor Promotes the Function of Myeloid-Derived Suppressor Cells by Suppressing HIF1 $\alpha$-Dependent Glycolysis. Cell Mol Immunol (2018) 15:618-29. doi: $10.1038 / \mathrm{cmi} .2017 .5$

100. Zhao Y, Wu T, Shao S, Shi B, Zhao Y. Phenotype, Development, and Biological Function of Myeloid-Derived Suppressor Cells. Oncoimmunology (2016) 5:1-12. doi: 10.1080/2162402X.2015.1004983

101. Park Y, Chung WJ, Choi DYo, Baek H, Jung SHWA, Choi ISUC, et al. Functional Class and Targeted Therapy Are Related to the Survival in Patients With Pulmonary Arterial Hypertension. Yonsei Med J (2014) 55:1526-32. doi: 10.3349/ymj.2014.55.6.1526

102. Lai YC, Potoka KC, Champion HC, Mora AL, Gladwin MT. Pulmonary Arterial Hypertension: The Clinical Syndrome. Circ Res (2014) 115:115-30. doi: 10.1161/CIRCRESAHA.115.301146

103. Xi X, Zhang J, Wang J, Chen Y, Zhang W, Zhang X, et al. Sgk1 Mediates Hypoxic Pulmonary Hypertension Through Promoting Macrophage Infiltration and Activation. Anal Cell Pathol (2019) 2019:1-10. doi: $10.1155 / 2019 / 3013765$

104. Schofield CJ, Ratcliffe PJ. Oxygen Sensing by HIF Hydroxylases. Nat Rev Mol Cell Biol (2004) 5:343-54. doi: 10.1038/nrm1366

105. Cummins EP, Keogh CE, Crean D, Taylor CT. The Role of HIF in Immunity and Inflammation. Mol Aspects Med (2016) 47-48:24-34. doi: 10.1016/ j.mam.2015.12.004

106. Campbell EL, Colgan SP. Neutrophils and Inflammatory Metabolism in Antimicrobial Functions of the Mucosa. J Leukoc Biol (2015) 98:517-22. doi: 10.1189/jlb.3mr1114-556r

107. Flück K, Fandrey J. Oxygen Sensing in Intestinal Mucosal Inflammation. Pflugers Arch Eur J Physiol (2016) 468:77-84. doi: 10.1007/s00424-015-1722-4

108. West JB. Are Permanent Residents of High Altitude Fully Adapted to Their Hypoxic Environment? High Alt Med Biol (2017) 18:135-9. doi: 10.1089/ ham.2016.0152
109. Hackett P, Roach R. High Altitude Ilness. N Engl J Med (2001) 345:107-14. doi: 10.1056/NEJM200107123450206

110. Pollard AJ, Murdoch DR, Bartsch P. Children in the Mountains. Br Med J (1998) 316:874-5. doi: 10.1001/jama.1980.03300370030022

111. Debudaj A, Bobiński R. The Pathophysiology of Acute Mountain Sickness. Pol Merkur Lekarski (2010) 28:478-81.

112. Luks AM, McIntosh SE, Grissom CK, Auerbach PS, Rodway GW, Schoene RB, et al. Wilderness Medical Society Consensus Guidelines for the Prevention and Treatment of Acute Altitude Illness. Wilderness Environ Med (2010) 21:146-55. doi: 10.1016/j.wem.2010.03.002

113. Imray C, Wright A, Subudhi A, Roach R. Acute Mountain Sickness: Pathophysiology, Prevention, and Treatment. Prog Cardiovasc Dis (2010) 52:467-84. doi: 10.1016/j.pcad.2010.02.003

114. Eltzschig HK, Carmeliet P. Hypoxia and Inflammation. N Engl J Med (2011) 364:656-65. doi: 10.1056/NEJMra0910283

115. Scherrer U, Vollenweider P, Randin D, Jéquier E, Nicod P, Tappy L. Suppression of Insulin-Induced Sympathetic Activation and Vasodilation by Dexamethasone in Humans. Circulation (1993) 88:388-94. doi: 10.1161/ 01.CIR.88.2.388

116. Kim H, Lee JM, Park JS, Jo SA, Kim YO, Kim CW, et al. Dexamethasone Coordinately Regulates Angiopoietin-1 and VEGF: A Mechanism of Glucocorticoid-Induced Stabilization of Blood-Brain Barrier. Biochem Biophys Res Commun (2008) 372:243-8. doi: 10.1016/j.bbrc.2008.05.025

117. Huo Y, Rangarajan P, Ling EA, Dheen ST. Dexamethasone Inhibits the NoxDependent ROS Production Via Suppression of MKP-1-Dependent MAPK Pathways in Activated Microglia. BMC Neurosci (2011) 12:1-18. doi: 10.1186/1471-2202-12-49

118. Berger MM, Macholz F, Sareban M, Schmidt P, Fried S, Dankl D, et al. Inhaled Budesonide Does Not Prevent Acute Mountain Sickness After Rapid Ascent to 4559 M. Eur Respir J (2017) 50:1-4. doi: 10.1183/13993003.00982-2017

119. Zhu X, Liu Y, Li N, He Q. Inhaled Budesonide for the Prevention of Acute Mountain Sickness: A Meta-Analysis of Randomized Controlled Trials. Am J Emerg Med (2020) 38:1627-34. doi: 10.1016/j.ajem.2019.158461

120. Pandit A, Karmacharya P, Pathak R, Giri S, Aryal MR. Efficacy of NSAIDs for the Prevention of Acute Mountain Sickness: A Systematic Review and Meta-Analysis. J Community Hosp Intern Med Perspect (2014) 4:1-7. doi: 10.3402/jchimp.v4.24927

121. Majmundar AJ, Wong WJ, Simon MC. Hypoxia-Inducible Factors and the Response to Hypoxic Stress. Mol Cell (2010) 40:294-309. doi: 10.1016/ j.molcel.2010.09.022

122. D'Ignazio L, Bandarra D, Rocha S. Nf-kb and HIF Crosstalk in Immune Responses. FEBS J (2016) 283:413-24. doi: 10.1111/febs.13578

123. Cummins EP, Berra E, Comerford KM, Ginouves A, Fitzgerald KT, Seeballuck F, et al. Prolyl Hydroxylase-1 Negatively Regulates Iкb Kinase$\beta$, Giving Insight Into Hypoxia-Induced Nfkb Activity. Proc Natl Acad Sci USA (2006) 103:18154-9. doi: 10.1073/pnas.0602235103

124. Yang W, Xia Y, Cao Y, Zheng Y, Bu W, Zhang L, et al. Egfr-Induced and Pkce Monoubiquitylation-Dependent Nf-kb Activation Upregulates PKM2 Expression and Promotes Tumorigenesis. Mol Cell (2012) 48:771-84. doi: 10.1016/j.molcel.2012.09.028

125. Bracken CP, Whitelaw ML, Peet DJ. Activity of Hypoxia-Inducible Factor $2 \alpha$ Is Regulated by Association With the NF- $\kappa \mathrm{b}$ Essential Modulator. J Biol Chem (2005) 280:14240-51. doi: 10.1074/jbc.M409987200

126. Wright CW, Duckett CS. The Aryl Hydrocarbon Nuclear Translocator Alters CD30-Mediated Nf-kb-Dependent Transcription. Science (2009) 323:251-5. doi: 10.1126/science.1162818

127. Déry MAC, Michaud MD, Richard DE. Hypoxia-Inducible Factor 1: Regulation by Hypoxic and Non-Hypoxic Activators. Int J Biochem Cell Biol (2005) 37:535-40. doi: 10.1016/j.biocel.2004.08.012

128. Van Uden P, Kenneth NS, Rocha S. Regulation of Hypoxia-Inducible Factor$1 \alpha$ a by NF-Kb. Biochem J (2008) 412:477-84. doi: 10.1042/BJ20080476

129. Rius J, Guma M, Schachtrup C, Akassoglou K, Zinkernagel AS, Nizet V, et al. Nf-kb Links Innate Immunity to the Hypoxic Response Through Transcriptional Regulation of HIF-1 $\alpha$. Nature (2008) 453:807-11. doi: 10.1038/nature06905

130. Peyssonnaux C, Cejudo-Martin P, Doedens A, Zinkernagel AS, Johnson RS, Nizet V. Cutting Edge: Essential Role of Hypoxia Inducible Factor-1 in Development of Lipopolysaccharide-Induced Sepsis. J Immunol (2007) 178:7516-9. doi: 10.4049/jimmunol.178.12.7516 
131. Hartmann G, Tschöp M, Fischer R, Bidlingmaier C, Riepl R, Tschöp K, et al. High Altitude Increases Circulating interleukin-6, Interleukin-1 Receptor Antagonist and C-Reactive Protein. Cytokine (2000) 12:246-52. doi: 10.1006/ cyto. 1999.0533

132. Mazzeo RS. Altitude, Exercise and Immune Function. Exerc Immunol Rev (2005) 11:6-16.

133. de Gonzalo-Calvo D, Neitzert K, Fernández M, Vega-Naredo I, Caballero B, García-Macía M, et al. Differential Inflammatory Responses in Aging and Disease: TNF- $\alpha$ and IL-6 as Possible Biomarkers. Free Radic Biol Med (2010) 49:733-7. doi: 10.1016/j.freeradbiomed.2010.05.019

134. Sarada SKS, Veeramohan HP, Mathew T, Saumya S, Chitharanjan M. Nifedipine Inhibits Hypoxia Induced Transvascular Leakage Through Down Regulation of Nfkb. Respir Physiol Neurobiol (2012) 183:26-34. doi: 10.1016/j.resp.2012.05.016

135. Mishra KP, Sharma N, Soree P, Gupta RK, Ganju L, Singh SB. HypoxiaInduced Inflammatory Chemokines in Subjects With a History of HighAltitude Pulmonary Edema. Indian J Clin Biochem (2016) 31:81-6. doi: $10.1007 / \mathrm{s} 12291-015-0491-3$

136. Chao J, Viets Z, Donham P, Wood JG, Gonzalez NC. Dexamethasone Blocks the Systemic Inflammation of Alveolar Hypoxia At Several Sites in the Inflammatory Cascade. Am J Physiol - Hear Circ Physiol (2012) 303:168-77. doi: 10.1152/ajpheart.00106.2012

137. Chao J, Wood JG, Gonzalez NC. Alveolar Macrophages Initiate the Systemic Microvascular Inflammatory Response to Alveolar Hypoxia. Respir Physiol Neurobiol (2011) 178:439-48. doi: 10.1016/j.resp.2011.03.008

138. Savaskan NE, Fingerle-Rowson G, Buchfelder M, Eyüpoglu IY. Brain Miffed by Macrophage Migration Inhibitory Factor. Int J Cell Biol (2012) 2012:1-11. doi: $10.1155 / 2012 / 139573$

139. Eichstaedt CA, Mairbäurl H, Song J, Benjamin N, Fischer C, Dehnert C, et al. Genetic Predisposition to High-Altitude Pulmonary Edema. High Alt Med Biol (2020) 21:28-36. doi: 10.1089/ham.2019.0083

140. Kammerer T, Faihs V, Hulde N, Stangl M, Brettner F, Rehm M, et al. Hypoxic-Inflammatory Responses Under Acute Hypoxia: In Vitro Experiments and Prospective Observational Expedition Trial. Int J Mol Sci (2020) 21:1-17. doi: 10.3390/ijms21031034

141. Song TT, Bi YH, Gao YQ, Huang R, Hao K, Xu G, et al. Systemic ProInflammatory Response Facilitates the Development of Cerebral Edema During Short Hypoxia. J Neuroinflamm (2016) 13:1-14. doi: 10.1186/ s12974-016-0528-4

142. Alexander BT, Dasinger JH, Intapad S. Fetal Programming and Cardiovascular Pathology. Compr Physiol (2015) 5:997-1025. doi: 10.1002/ cphy.c140036.Fetal

143. Lv J, Ma Q, Dasgupta C, Xu Z, Zhang L. Antenatal Hypoxia and Programming of Glucocorticoid Receptor Expression in the Adult Rat Heart. Front Pediatr (2019) 10:323. doi: 10.3389/fphys.2019.00323

144. Low JA, Froese AB, Galbraith RS, Smith JT, Sauerbrei EE, Derrick EJ. The Association Between Preterm Newborn Hypotension and Hypoxemia and Outcome During the First Year. Acta Paediatr (1993) 82:433-7. doi: 10.1111/ j.1651-2227.1993.tb12717.x

145. Rubaltelli FF, Bonafè L, Tangucci M, Spagnolo A, Dani C. Epidemiology of Neonatal Acute Respiratory Disorders A Multicenter Study on Incidence and Fatality Rates of. Biol Neonate (1998) 74:7-15. doi: 10.1159/ 000014005

146. Reyes ZC, Claure N, Tauscher MK, Ugard CD, Vanbuskirk S, Bancalari E. Randomized, Controlled Trial Comparing Synchronized Intermittent Mandatory Ventilation and Synchronized Intermittent Mandatory Ventilation Plus Pressure Support in Preterm Infants. Pediatrics (2006) 118:1409-17. doi: 10.1542/peds.2005-2923

147. Chang M. Optimal Oxygen Saturation in Premature Infants. Korean Peadiatric Soc (2011) 54:359-62. doi: 10.3345/kjp.2011.54.9.359

148. Hanukoglu A, Fried D, Nakash I, Hanukoglu I. Selective Increases in Adrenal Respiratory Disease in Infants Steroidogenic Capacity During Acute
Respiratory Disease in Infants. Eur J Endocrinol (1995) 133:552-6. doi: 10.1530/eje.0.1330552

149. Raff H, Jankowski BM, Bruder ED, Engeland WC, Oaks MK. The Effect of Hypoxia From Birth on the Regulation of Aldosterone in the 7-Day-Old Rat: Plasma Hormones, Steroidogenesis in Vitro, and Steroidogenic Enzyme Messenger Ribonucleic Acid. Endocrinology (1999) 140:3147-53. doi: 10.1210/endo.140.7.6794

150. Raff H, Jankowski BM, Engeland WC, Oaks MK. Hypoxia In Vivo Inhibits Aldosterone Synthesis and Aldosterone Synthase mRNA in Rats. J Appl (1996) 81:604-10. doi: 10.1152/jappl.1996.81.2.604

151. Raff H, Jacobson L, Cullinan WE. Augmented Hypothalamic Corticotrophin-Releasing Hormone mRNA and Corticosterone Responses to Stress in Adult Rats Exposed to Perinatal Hypoxia. J Neuroendocr (2007) 19:907-12. doi: 10.1016/j.cortex.2009.08.003.Predictive

152. Vetrovoy O, Tyulkova E, Stratilov V, Baranova K, Nimiritsky P, Makarevich $\mathrm{P}$, et al. Long-Term Effects of Prenatal Severe Hypoxia on Central and Peripheral Components of the Glucocorticoid System in Rats. Dev Neurosci (2021) 42:145-58. doi: 10.1159/000512223

153. Gonzalez-rodriguez PJ, Xiong F, Li Y, Zhou J, Zhang L. Fetal Hypoxia Increases Vulnerability of Hypoxic - Ischemic Brain Injury in Neonatal Rats: Role of Glucocorticoid Receptors. Neurobiol Dis (2014) 65:172-9. doi: 10.1016/j.nbd.2014.01.020

154. Chen W, Jadhav V, Tang J, Zhang JH. Hif-1a Inhibition Ameliorates Neonatal Brain Injury in a Rat Pup Hypoxic-Ischemic Model. Neurobiol Dis (2008) 31:433-41. doi: 10.1016/j.nbd.2008.05.020.HIF-1

155. Sierra A, Gottfried-Blackmore A, Milner TA, McEwen BS, Bulloch K. Steroid Hormone Receptor Expression and Function in Microglia. Glia (2008) 56:659-74. doi: 10.1002/glia.20644

156. Feng Y, Lu S, Wang J, Kumar P, Zhang L, Bhatt AJ. Dexamethasone-Induced Neuroprotection in Hypoxic-Ischemic Brain Injury in Newborn Rats Is Partly Mediated Via Akt Activation. Brain Res (2014) 1589:68-77. doi: 10.1016/j.brainres.2014.09.073

157. Ekert P, MacLusky N, Luo XP, Lehotay DC, Smith B, Post M, et al. Dexamethasone Prevents Apoptosis in a Neonatal Rat Model of HypoxicIschemic Encephalopathy (HIE) by a Reactive Oxygen Species-Independent Mechanism. Brain Res (1997) 747:9-17. doi: 10.1016/S0006-8993(96)01201-2

158. Feng Y, Rhodes PG, Bhatt AJ. Dexamethasone Pre-Treatment Protects Brain Against Hypoxic-Ischemic Injury Partially Through Up-Regulation of Vascular Endothelial Growth Factor A in Neonatal Rats. Neuroscience (2011) 179:223-32. doi: 10.1016/j.neuroscience.2011.01.050

159. Yeh CY, Yeh CM, Yu TH, Chang KH, Huang CC. Hsu K Sen. Neonatal Dexamethasone Treatment Exacerbates Hypoxia/Ischemia-Induced White Matter Injury. Mol Neurobiol (2017) 54:7083-95. doi: 10.1007/s12035-0160241-4

160. Dallas M, Boycott HE, Atkinson L, Miller A, Boyle JP, Pearson HA, et al. Hypoxia Suppresses Glutamate Transport in Astrocytes. J Neurosci (2007) 27:3946-55. doi: 10.1523/JNEUROSCI.5030-06.2007

161. Tan X, Chen Y, Li J, Li X, Miao Z, Xin N, et al. The Inhibition of Cdk5 Activity After Hypoxia/Ischemia Injury Reduces Infarct Size and Promotes Functional Recovery in Neonatal Rats. Neuroscience (2015) 290:552-60. doi: 10.1016/j.neuroscience.2015.01.054

Conflict of Interest: The authors declare that the research was conducted in the absence of any commercial or financial relationships that could be construed as a potential conflict of interest.

Copyright $\odot 2021$ Vanderhaeghen, Beyaert and Libert. This is an open-access article distributed under the terms of the Creative Commons Attribution License (CC BY). The use, distribution or reproduction in other forums is permitted, provided the original author(s) and the copyright owner(s) are credited and that the original publication in this journal is cited, in accordance with accepted academic practice. No use, distribution or reproduction is permitted which does not comply with these terms. 